4

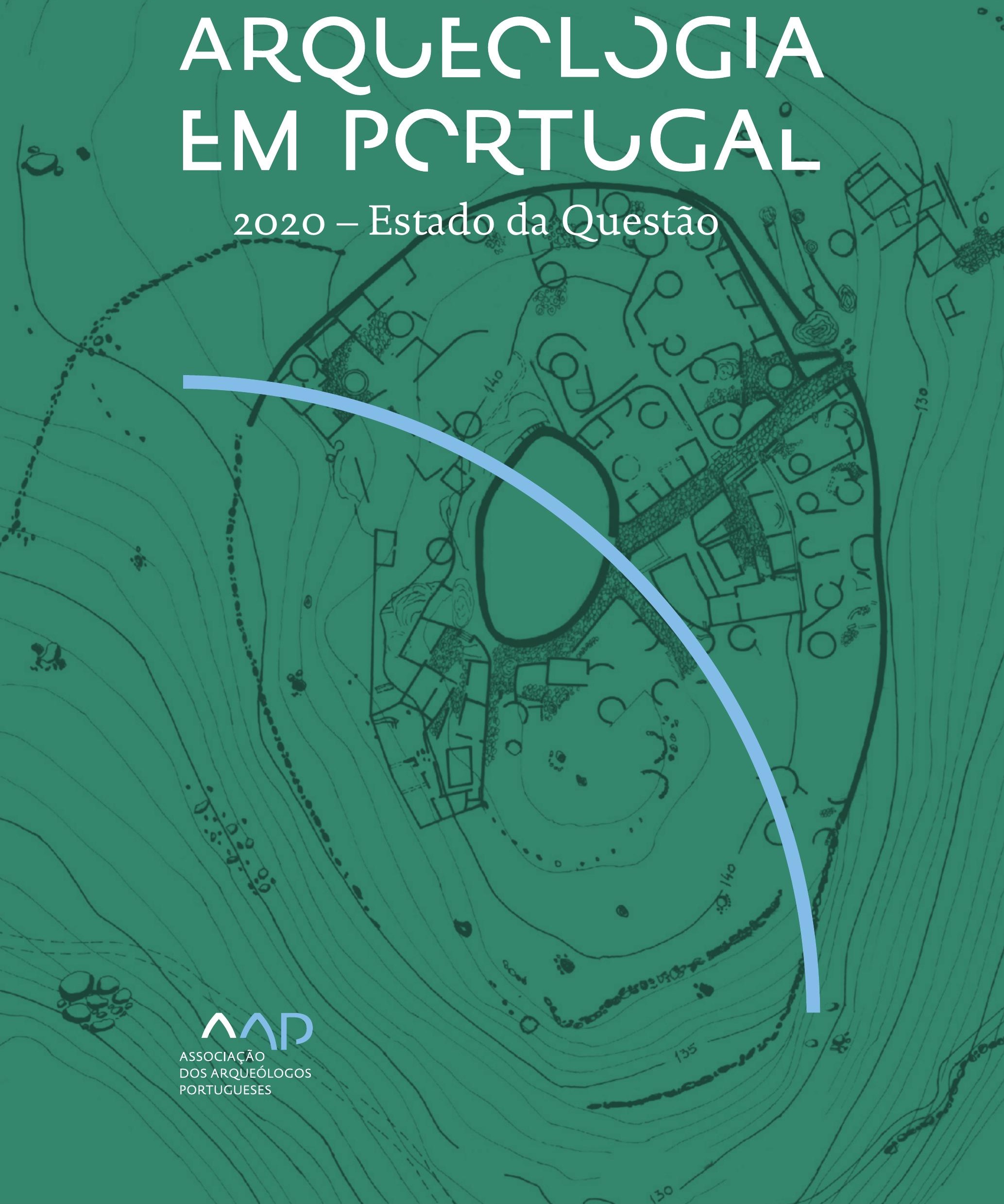


Coordenação editorial: José Morais Arnaud, César Neves e Andrea Martins Design gráfico: Flatland Design

AAP - ISBN: 978-972-9451-89-8

CITCEM - ISBN: 978-989-8970-25-1

Associação dos Arqueólogos Portugueses e CITCEM

Lisboa, 2020

O conteúdo dos artigos é da inteira responsabilidade dos autores. Sendo assim a Associação dos Arqueólogos Portugueses declina qualquer responsabilidade por eventuais equívocos ou questões de ordem ética e legal.

Desenho de capa:

Planta do castro de Monte Mozinho (Museu Municipal de Penafiel).

\section{$\hat{\wedge} \mathrm{P}$}

DOS ARQUEÓLOGOS PORTUGUESES

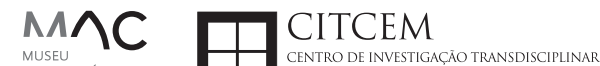
MUSEU
ARQUELLÓGICO
DO CARMO
U.PORTO

FLUP FACULDADE DE LETRAS
UNIVERSIDADE DO PORTO

Apoio

EC para a Ciência 


\section{Índice}

15 Prefácio

José Morais Arnaud

\section{Historiografia e Teoria}

17 Território, comunidade, memória e emoção: a contribuição da história da arqueologia (algumas primeiras e breves reflexões)

Ana Cristina Martins

25 Como descolonizar a arqueologia portuguesa?

Rui Gomes Coelho

41 Arqueologia e Modernidade: uma revisitação pessoal e breve de alguns aspetos da obra homónima de Julian Thomas de 2004

Vítor Oliveira Jorge

57 Dados para a História das Mulheres na Arqueologia portuguesa, dos finais do século XIX aos inícios do século XX: números, nomes e tabelas

Filipa Dimas / Mariana Diniz

73 Retractos da arqueologia portuguesa na imprensa: (in)visibilidades no feminino

Catarina Costeira / Elsa Luís

85 Arqueologia e Arqueólogos no Norte de Portugal Jacinta Bugalhão

101 Vieira Guimarães (1864-1939) e a arqueologia em Tomar: uma abordagem sobre o território e as gentes

João Amendoeira Peixoto / Ana Cristina Martins

115 Os memoráveis? A arqueologia algarvia na imprensa nacional e regional na presente centúria (2001-2019): características, visões do(s) passado(s) e a arqueologia

enquanto marca

Frederico Agosto / João Silva

129 A Evolução da Arqueologia Urbana e a Valorização Patrimonial no Barlavento Algarvio: Os casos de Portimão e Silves

Artur Mateus / Diogo Varandas / Rafael Boavida

\section{Gestão, Valorização e Salvaguarda do Património}

145 O Caderno Reivindicativo e as condições de trabalho em Arqueologia Miguel Rocha / Liliana Matias Carvalho / Regis Barbosa / Mauro Correia / Sara Simões / Jacinta Bugalhão / Sara Brito / Liliana Veríssimo Carvalho / Richard Peace / Pedro Peça / Cézer Santos

155 Os Estudos de Impacte Patrimonial como elemento para uma estratégia sustentável de minimização de impactes no âmbito de reconversões agrícolas Tiago do Pereiro

165 Salvaguarda de Património arqueológico em operações florestais: gestão e sensibilização Filipa Bragança / Gertrudes Zambujo / Sandra Lourenço / Belém Paiva / Carlos Banha / Frederico Tatá Regala / Helena Moura / Jacinta Bugalhão / João Marques / José Correia / Pedro Faria / Samuel Melro

179 Os valores do Património: uma investigação sobre os Sítios Pré-históricos de Arte Rupestre do Vale do Rio Côa e de Siega Verde José Paulo Francisco 
189 Conjugando recursos arqueológicos e naturais para potenciar as visitas ao Geoparque Litoral de Viana do Castelo (Noroeste de Portugal)

Hugo A. Sampaio / Ana M.S. Bettencourt / Susana Marinho / Ricardo Carvalhido

203 Áreas de Potencial Arqueológico na Região do Médio Tejo: Modelo Espacial Preditivo Rita Ferreira Anastácio / Ana Filipa Martins / Luiz Oosterbeek

223 Património Arqueológico e Gestão Territorial: O contributo da Arqueologia para a revisão do PDM de Avis

Ana Cristina Ribeiro

237 A coleção arqueológica do extinto Museu Municipal do Porto - Origens, Percursos e Estudos

Sónia Couto

251 Valpaços - uma nova carta arqueológica

Pedro Pereira / Maria de Fátima Casares Machado

263 Arqueologia na Cidade de Peniche

Adriano Constantino / Luís Rendeiro

273 Arqueologia Urbana: a cidade de Lagos como caso de Estudo Cátia Neto

285 Estratégias de promoção do património cultural subaquático nos Açores. O caso da ilha do Faial

José Luís Neto / José Bettencourt / Luís Borges / Pedro Parreira

297 Carta Arqueológica da Cidade Velha: Uma primeira abordagem

Jaylson Monteiro / Nireide Tavares / Sara da Veiga / Claudino Ramos / Edson Brito /

Carlos Carvalho / Francisco Moreira / Adalberto Tavares

311 Antropologia Virtual: novas metodologias para a análise morfológica e funcional Ricardo Miguel Godinho / Célia Gonçalves

\section{Didáctica da Arqueologia}

327 Como os projetos de Arqueologia podem contribuir para uma comunidade culturalmente mais consciente Alexandra Figueiredo / Claúdio Monteiro / Adolfo Silveira / Ricardo Lopes

337 Educação Patrimonial - Um cidadão esclarecido é um cidadão ativo! Ana Paula Almeida

351 A aproximação da Arqueologia à sala de aula: um caso de estudo no $3^{\circ}$ ciclo do Ensino Básico Luís Serrão Gil

363 Arqueologia 3.o - Pensar e comunicar a Arqueologia para um futuro sustentável Mónica Rolo

377 “Conversa de Arqueólogos" - Divulgar a Arqueologia em tempos de Pandemia Diogo Teixeira Dias

389 Escola Profissional de Arqueologia: desafios e oportunidades Susana Nunes / Dulcineia Pinto / Júlia Silva / Ana Mascarenhas

399 Os Museus de Arqueologia e os Jovens: a oferta educativa para o público adolescente Beatriz Correia Barata / Leonor Medeiros

411 O museu universitário como mediador entre a ciência e a sociedade: o exemplo da secção de arqueologia no Museu de História Natural e da Ciência da Universidade do Porto (MHNC-UP)

Rita Gaspar 
421 Museu de Lanifícios: Real Fábrica de Panos. Atividades no âmbito da Arqueologia Beatriz Correia Barata / Rita Salvado

427 Arqueologia Pública e o caso da localidade da Mata (Torres Novas) Cláudia Manso / Ana Rita Ferreira / Cristiana Ferreira / Vanessa Cardoso Antunes

431 Do sítio arqueológico ao museu: um percurso (também) didático Lídia Fernandes

447 Estão todos convidados para a Festa! E para dançar também... O projecto do Serviço Educativo do Museu Arqueológico do Carmo na $5^{\underline{a}}$ Edição da Festa da Arqueologia Rita Pires dos Santos

459 O “Clã de Carenque”, um projeto didático de arqueologia Eduardo Gonzalez Rocha

469 Mediação cultural: peixe que puxa carroça nas Ruínas Romanas de Troia Inês Vaz Pinto / Ana Patrícia Magalhães / Patrícia Brum / Filipa Santos

481 Didática Arqueológica, experiências do Projeto Mértola Vila Museu Maria de Fátima Palma / Clara Rodrigues / Susana Gómez / Lígia Rafael

\section{Arte Rupestre}

497 Os inventários de arte rupestre em Portugal Mila Simões de Abreu

513 O projeto FIRST-ART - conservação, documentação e gestão das primeiras manifestações de arte rupestre no Sudoeste da Península Ibérica: as grutas do Escoural e Maltravieso Sara Garcês / Hipólito Collado / José Julio García Arranz / Luiz Oosterbeek / António Carlos Silva / Pierluigi Rosina / Hugo Gomes / Anabela Borralheiro Pereira / George Nash / Esmeralda Gomes / Nelson Almeida / Carlos Carpetudo

523 Trabalhos de documentação de arte paleolítica realizados no âmbito do projeto PalæoCôa André Tomás Santos / António Fernando Barbosa / Luís Luís / Marcelo Silvestre / Thierry Aubry

537 Imagens fantasmagóricas, silhuetas elusivas: as figuras humanas na arte do Paleolítico Superior da região do Côa Mário Reis

$55^{1}$ Os motivos zoomórficos representados nas placas de tear de Vila Nova de São Pedro (Azambuja, Portugal) Andrea Martins / César Neves / José M. Arnaud / Mariana Diniz

571 Arte Rupestre do Monte de Góios (Lanhelas, Caminha). Síntese dos resultados dos trabalhos efectuados em 2007-2009 Mário Varela Gomes

599 Gravuras rupestres de barquiformes no Monte de S. Romão, Guimarães, Noroeste de Portugal Daniela Cardoso

613 Círculos segmentados gravados na Bacia do Rio Lima (Noroeste de Portugal): contributos para o seu estudo Diogo Marinho / Ana M.S. Bettencourt / Hugo Aluai Sampaio

631 Equídeos gravados no curso inferior do Rio Mouro, Monção (NW Portugal). Análise preliminar Coutinho, L.M. / Bettencourt, A.M.S / Sampaio, Hugo A.S

645 Paletas na Arte Rupestre do Noroeste de Portugal. Inventário preliminar Bruna Sousa Afonso / Ana M. S. Bettencourt / Hugo A. Sampaio 


\section{Pré-História}

661 O projeto Miño/Minho: balanço de quatro anos de trabalhos arqueológicos Sérgio Monteiro-Rodrigues / João Pedro Cunha-Ribeiro / Eduardo Méndez-Quintas / Carlos Ferreira / Pedro Xavier / José Meireles / Alberto Gomes / Manuel Santonja / Alfredo Pérez-González

677 A ocupação paleolítica da margem esquerda do Baixo Minho: a indústria lítica do sítio de Pedreiras 2 (Monção, Portugal) e a sua integração no contexto regional Carlos Ferreira / João Pedro Cunha-Ribeiro / Sérgio Monteiro-Rodrigues / Eduardo Méndez-Quintas / Pedro Xavier / José Meireles / Alberto Gomes / Manuel Santonja / Alfredo Pérez-González

693 O sítio acheulense do Plistocénico médio da Gruta da Aroeira Joan Daura / Montserrat Sanz / Filipa Rodrigues / Pedro Souto / João Zilhão

703 As sociedades neandertais no Barlavento algarvio: modelos preditivos com recurso aos SIG

Daniela Maio

715 A utilização de quartzo durante o Paleolítico Superior no território dos vales dos rios Vouga e Côa

Cristina Gameiro / Thierry Aubry / Bárbara Costa / Sérgio Gomes / Luís Luís / Carmen Manzano / André Tomás Santos

733 Uma perspetiva diacrónica da ocupação do concheiro do Cabeço da Amoreira (Muge, Portugal) a partir da tecnologia lítica Joana Belmiro / João Cascalheira / Célia Gonçalves

745 Novos dados sobre a Pré-história Antiga no concelho de Palmela. A intervenção arqueológica no sítio do Poceirão I

Michelle Teixeira Santos

757 Problemas em torno de Datas Absolutas Pré-Históricas no Norte do Alentejo Jorge de Oliveira

771 Povoamento pré-histórico nas áreas montanhosas do NO de Portugal: o Abrigo 1 de Vale de Cerdeira Pedro Xavier / José Meireles / Carlos Alves

783 Apreciação do povoamento do Neolítico Inicial na Baixa Bacia do Douro. A Lavra I (Serra da Aboboreira) como caso de estudo Maria de Jesus Sanches

797 O Processo de Neolitização na Plataforma do Mondego: os dados do Sector C do Outeiro dos Castelos de Beijós (Carregal do Sal)

João Carlos de Senna-Martinez / José Manuel Quintã Ventura / Andreia Carvalho / Cíntia Maurício

823 Novos trabalhos na Lapa da Bugalheira (Almonda, Torres Novas) Filipa Rodrigues / Pedro Souto / Artur Ferreira / Alexandre Varanda / Luís Gomes / Helena Gomes / João Zilhão

837 A pedra polida e afeiçoada do sítio do Neolítico médio da Moita do Ourives (Benavente, Portugal)

César Neves

857 Casal do Outeiro (Encarnação, Mafra): novos contributos para o conhecimento do povoamento do Neolítico final na Península de Lisboa.

Cátia Delicado / Carlos Maneira e Costa / Marta Miranda / Ana Catarina Sousa

873 Stresse infantil, morbilidade e mortalidade no sítio arqueológico do Neolítico Final/ Calcolítico ( $4^{\circ}$ e $3^{\circ}$ milénio a.C.) do Monte do Carrascal 2 (Ferreira do Alentejo, Beja) Liliana Matias de Carvalho / Sofia N. Wasterlain 
885 Come together: O Conjunto Megalítico das Motas (Monção, Viana do Castelo) e as expressões Campaniformes do Alto Minho Ana Catarina Basílio / Rui Ramos

899 Trabalhos arqueológicos no sítio Calcolítico da Pedreira do Poio Carla Magalhães / João Muralha / Mário Reis / António Batarda Fernandes

913 O sítio arqueológico de Castanheiro do Vento. Da arquitectura do sítio à arquitectura de um território João Muralha Cardoso

925 Estudo zooarqueológico das faunas do Calcolítico final de Vila Nova de São Pedro (Azambuja, Portugal): Campanhas de 2017 e 2018 Cleia Detry / Ana Catarina Francisco / Mariana Diniz / Andrea Martins / César Neves / José Morais Arnaud

943 As faunas depositadas no Museu Arqueológico do Carmo provenientes de Vila Nova de São Pedro (Azambuja): as campanhas de 1937 a 1967 Ana Catarina Francisco / Cleia Detry / César Neves / Andrea Martins / Mariana Diniz / José Morais Arnaud

959 Análise funcional de material lítico em sílex do castro de Vila Nova de S. Pedro (Azambuja, Portugal): uma primeira abordagem Rafael Lima

971 O recinto da Folha do Ouro 1 (Serpa) no contexto dos recintos de fossos calcolíticos alentejanos

António Carlos Valera / Tiago do Pereiro / Pedro Valério / António M. Monge Soares

\section{Proto-História}

987 Produção de sal marinho na Idade do Bronze do noroeste Português. Alguns dados para uma reflexão

Ana M. S. Bettencourt / Sara Luz / Nuno Oliveira / Pedro P. Simões / Maria Isabel C. Alves / Emílio Abad-Vidal

1001 A estátua-menir do Pedrão ou de São Bartolomeu do Mar (Esposende, noroeste de Portugal) no contexto arqueológico da fachada costeira de entre os rios Neiva e Cávado Ana M. S. Bettencourt / Manuel Santos-Estévez / Pedro Pimenta Simões / Luís Gonçalves

1015 O Castro do Muro (Vandoma/Baltar, Paredes) - notas para uma biografia de ocupação da Idade do Bronze à Idade Média

Maria Antónia D. Silva / Ana M. S. Bettencourt / António Manuel S. P. Silva / Natália Félix

1031 Do Bronze Final à Idade Média - continuidades e hiatos na ocupação de Povoados em Oliveira de Azeméis João Tiago Tavares / Adriaan de Man

1041 As faunas do final da Idade do Bronze no Sul de Portugal: leituras desde o Outeiro do Circo (Beja)

Nelson J. Almeida / Íris Dias / Cleia Detry / Eduardo Porfírio / Miguel Serra

1055 A Espada do Monte das Oliveiras (Serpa) - uma arma do Bronze Pleno do Sudoeste Rui M. G. Monge Soares / Pedro Valério / Mariana Nabais / António M. Monge Soares

1065 São Julião da Branca (Albergaria-a-Velha) - Investigação e valorização de um povoado do Bronze Final

António Manuel S. P. Silva / Paulo A. P. Lemos / Sara Almeida e Silva / Edite Martins de Sá

1083 Do castro de S. João ao Mosteiro de Santa Clara: notícia de uma intervenção arqueológica, em Vila do Conde Rui Pinheiro 
1095 O castro de Ovil (Espinho), um quarto de século de investigação - resultados e questões em aberto

Jorge Fernando Salvador / António Manuel S. P. Silva

1111 O Castro de Salreu (Estarreja), um povoado proto-histórico no litoral do Entre Douro e Vouga

Sara Almeida e Silva / António Manuel S. P. Silva / Paulo A. P. Lemos / Edite Martins de Sá

1127 Castro de Nossa Senhora das Necessidades (Sernancelhe): uma primeira análise artefactual Telma Susana O. Ribeiro

${ }_{1141}$ A cividade de Bagunte. O estado atual da investigação Pedro Brochado de Almeida

1153 Zoomorfos na cerâmica da Idade do Ferro no NW Peninsular: inventário, cronologias e significado Nuno Oliveira / Cristina Seoane

1163 Vasos gregos em Portugal: diferentes maneiras de contar a história do intercâmbio cultural na Idade do Ferro

Daniela Ferreira

1175 Os exotica da necrópole da Idade do Ferro do Olival do Senhor dos Mártires (Alcácer do Sal) no seu contexto regional

Francisco B. Gomes

\section{Antiguidade Clássica e Tardia}

1191 O uso de madeira como combustível no sítio da Quinta de Crestelos (Baixo Sabor): da Idade do Ferro à Romanização Filipe Vaz / João Tereso / Sérgio Simões Pereira / José Sastre / Javier Larrazabal Galarza / Susana Cosme / José António Pereira / Israel Espi

1207 Cultivos de Época Romana no Baixo Sabor: continuidade em tempos de mudança? João Pedro Tereso / Sérgio Simões Pereira / Filipe Santos / Luís Seabra / Filipe Vaz

1221 A casa romana na Hispânia: aplicação dos modelos itálicos nas províncias ibéricas Fernanda Magalhães / Diego Machado / Manuela Martins

1235 As pinturas murais romanas da Rua General Sousa Machado, n. ${ }^{5}$ 1, Chaves José Carvalho

1243 Trás do Castelo (Vale de Mir, Pegarinhos, Alijó) - Uma exploração agrícola romana do Douro

Tony Silvino / Pedro Pereira

1255 A sequência de ocupação no quadrante sudeste de Bracara Augusta: as transformações de uma unidade doméstica Lara Fernandes / Manuela Martins

1263 Os Mosaicos com decoração geométrica e geométrico-vegetalista dos sítios arqueológicos da área do Conuentus Bracaraugustanus. Novas abordagens quanto à conservação, restauro, decoração e datação Maria de Fátima Abraços / Licínia Wrench

1277 “Casa Romana” do Castro de São Domingos (Cristelos, Lousada): Escavação, Estudo e Musealização Paulo André de P. Lemos

1291 A arqueobotânica no Castro de Guifões (Matosinhos, Noroeste de Portugal): O primeiro estudo carpológico

Luís Seabra / Andreia Arezes / Catarina Magalhães / José Varela / João Pedro Tereso 
1305 Um Horreum Augustano na Foz do Douro (Monte do Castelo de Gaia, Vila Nova de Gaia) Rui Ramos

1311 Ponderais romanos na Lusitânia: padrões, formas, materiais e contextos de utilização Diego Barrios Rodríguez

1323 Um almofariz centro-itálico na foz do Mondego

Marco Penajoia

1335 Estruturas romanas de Carnide - Lisboa Luísa Batalha / Mário Monteiro / Guilherme Cardoso

1347 O contexto funerário do sector da "necrópole NO" da Rua das Portas de S. Antão (Lisboa): o espaço, os artefactos, os indivíduos e a sua interconectividade na interpretação do passado Sílvia Loja, José Carlos Quaresma, Nelson Cabaço, Marina Lourenço, Sílvia Casimiro, Rodrigo Banha da Silva, Francisca Alves-Cardoso

${ }_{1361}$ Povoamento em época Romana na Amadora - resultados de um projeto pluridisciplinar Gisela Encarnação / Vanessa Dias

1371 A Arquitectura Residencial em Mirobriga (Santiago do Cacém): contributo a partir de um estudo de caso Filipe Sousa / Catarina Felício

${ }_{1385}$ O fim do ciclo. Saneamento e gestão de resíduos nos edifícios termais de Mirobriga (Santiago do Cacém)

Catarina Felício / Filipe Sousa

1399 Balsa, Topografia e Urbanismo de uma Cidade Portuária Vítor Silva Dias / João Pedro Bernardes / Celso Candeias / Cristina Tété Garcia

1413 No Largo das Mouras Velhas em Faro (2017): novas evidências da necrópole norte de Ossonoba e da sua ocupação medieval Ricardo Costeira da Silva / Paulo Botelho / Fernando Santos / Liliana Nunes

1429 Instrumentos de pesca recuperados numa fábrica de salga em Ossonoba (Faro) Inês Rasteiro / Ricardo Costeira da Silva / Paulo Botelho

1439 A Necrópole Romana do Eirô, Duas Igrejas (Penafiel): intervenção arqueológica de 2016 Laura Sousa / Teresa Soeiro

1457 Ritual, descarte ou afetividade? A presença de Canis lupus familiaris na Necrópole Noroeste de Olisipo (Lisboa)

Beatriz Calapez Santos / Sofia Simões Pereira / Rodrigo Banha da Silva / Sílvia Casimiro / Cleia Detry / Francisca Alves Cardoso

1467 Dinâmicas económicas em Bracara na Antiguidade Tardia Diego Machado / Manuela Martins / Fernanda Magalhães / Natália Botica

1479 Cerâmicas e Vidros da Antiguidade Tardia do Edifício sob a Igreja do Bom Jesus (Vila Nova de Gaia) Joaquim Filipe Ramos

1493 Novos contributos para a topografia histórica de Mértola no período romano e na Antiguidade Tardia Virgílio Lopes

\section{8. Época Medieval}

1511 Cerâmicas islâmicas no Garb setentrional "português": algumas evidências e incógnitas Constança dos Santos / Helena Catarino / Susana Gómez / Maria José Gonçalves / Isabel Inácio / Gonçalo Lopes / Jacinta Bugalhão / Sandra Cavaco / Jaquelina Covaneiro / Isabel Cristina Fernandes / Ana Sofia Gomes 
1525 Contributo para o conhecimento da cosmética islâmica, em Silves, durante a Idade Média Rosa Varela Gomes

1537 Yábura e o seu território - uma análise histórico-arqueológica de Évora entre os séculos VIII-XII José Rui Santos

1547 A encosta sul do Castelo de Palmela - resultados preliminares da escavação arqueológica Luís Filipe Pereira / Michelle Teixeira Santos

1559 A igreja de São Lourenço (Mouraria, Lisboa): um conjunto de silos e de cerâmica medieval islâmica

Andreia Filipa Moreira Rodrigues

1571 O registo material de movimentações populacionais no Médio Tejo, durante os séculos XII-XIII. Dois casos de "sunken featured buildings", nos concelhos de Cartaxo e Torres Novas Marco Liberato / Helena Santos / Nuno Santos

1585 O nordeste transmontano nos alvores da Idade média. Notas para reflexão Ana Maria da Costa Oliveira

1601 Sepulturas escavadas na rocha do Norte de Portugal e do Vale do Douro: primeiros resultados do Projecto SER-NPVD

Mário Jorge Barroca / César Guedes / Andreia Arezes / Ana Maria Oliveira

1619 "Portucalem Castrum Novum" entre o Mediterrâneo e o Atlântico: o estudo dos materiais cerâmicos alto-medievais do arqueossítio da rua de D. Hugo, nํ. 5 (Porto) João Luís Veloso

1627 A Alta Idade Média na fronteira de Lafões: notas preliminares sobre a Arqueologia no Concelho de Vouzela

Manuel Luís Real / Catarina Tente

1641 Um conjunto cerâmico medieval fora de portas: um breve testemunho aveirense Susana Temudo

${ }_{1651}$ Os Lóios do Porto: uma perspetiva integrada no panorama funerário da Baixa Idade Média à Época Moderna em meios urbanos em Portugal

Ana Lema Seabra

1659 O Caminho Português Interior de Santiago como eixo viário na Idade Média Pedro Azevedo

1665 Morfologia Urbana: Um exercício em torno do Castelo de Ourém André Donas-Botto / Jaqueline Pereira

1677 Intervenção arqueológica na Rua Marquês de Pombal/Largo do Espírito Santo (Bucelas, Loures)

Florbela Estêvão / Nathalie Antunes-Ferreira / Dário Ramos Neves / Inês Lisboa

1691 O Cemitério Medieval do Poço do Borratém e a espacialidade funerária na cidade de Lisboa Inês Belém / Vanessa Filipe / Vasco Noronha Vieira / Sónia Ferro / Rodrigo Banha da Silva

1705 Um Espaço Funerário Conventual do séc. XV em Lisboa: o caso do Convento de São Domingos da Cidade Sérgio Pedroso / Sílvia Casimiro / Rodrigo Banha da Silva / Francisca Alves Cardoso

\section{9. Época Moderna e Contemporânea}

1721 Arqueologia Moderna em Portugal: algumas reflexões críticas em torno da quantificação de conjuntos cerâmicos e suas inferências históricas e antropológicas Rodrigo Banha da Silva / André Bargão / Sara da Cruz Ferreira

1733 Faianças de dois contextos entre os finais do século XVI e XVIII do Palácio dos Condes de Penafiel, Lisboa

Martim Lopes / Tomás Mesquita 
1747 Um perfil de consumo do século XVIII na foz do Tejo: O caso do Mercado da Ribeira, Lisboa Sara da Cruz Ferreira / Rodrigo Banha da Silva / André Bargão

1761 Os Cachimbos dos Séculos XVII e XVIII do Palácio Mesquitela e Convento dos Inglesinhos (Lisboa)

Inês Simão / Marina Pinto / João Pimenta / Sara da Cruz Ferreira / André Bargão / Rodrigo Banha da Silva

1775 "Tomar os fumos da erua que chamão em Portugal erua sancta». Estudo de Cachimbos provenientes da Rua do Terreiro do Trigo, Lisboa

Miguel Martins de Sousa / José Pedro Henriques / Vanessa Galiza Filipe

1787 Cachimbos de Barro Caulínitico da Sé da Cidade Velha (República de Cabo Verde)

Rodrigo Banha da Silva / João Pimenta / Clementino Amaro

1801 Algumas considerações sobre espólio não cerâmico recuperado no Largo de Jesus (Lisboa) Carlos Boavida

1815 Adereços de vidro, dos séculos XVI-XVIII, procedentes do antigo Convento de Santana de Lisboa (anéis, braceletes e contas)

Joana Gonçalves / Rosa Varela Gomes / Mário Varela Gomes

1837 Da ostentação, luxo e poder à simplicidade do uso quotidiano: arqueologia e simbologia de joias e adornos da Idade Moderna Portuguesa Jéssica Iglésias

1849 Os amuletos em Portugal - dos objetos às superstições: o coral vermelho Alexandra Vieira

1865 Cerâmicas de Vila Franca de Xira nos séculos XV e XVI Eva Pires

1879 «Não passa por teu o que me pertence». Marcas de individualização associadas a faianças do Convento de Nossa Senhora de Aracoeli, Alcácer do Sal Catarina Parreira / Íris Fragoso / Miguel Martins de Sousa

1891 Cerâmica de Leiria: alguns focos de produção

Jaqueline Pereira / André Donas-Botto

1901 Os Fornos na Rua da Biquinha, em Óbidos Hugo Silva / Filipe Oliveira

1909 A casa de Pêro Fernandes, contador dos contos de D. Manuel I: o sítio arqueológico da Silha do Alferes, Seixal (século XVI) Mariana Nunes Ferreira

1921 O Alto da Vigia (Sintra) e a vigilância e defesa da costa Alexandre Gonçalves / Sandra Santos

1937 O contexto da torre sineira da Igreja de Santa Maria de Loures Paulo Calaveira / Martim Lopes

1949 A Necrópole do Hospital Militar do Castelo de São Jorge e as práticas funerárias na Lisboa de Época Moderna Susana Henriques / Liliana Matias de Carvalho / Ana Amarante / Sofia N. Wasterlain

1963 SAND - Sarilhos Grandes Entre dois Mundos: o adro da Igreja e a Paleobiologia dos ossos humanos recuperados

Paula Alves Pereira / Roger Lee Jesus / Bruno M. Magalhães

1975 Expansão urbana da vila de Cascais no século XVII e XVIII: a intervenção arqueológica na Rua da Vitória no 15 a 17

Tiago Pereira / Vanessa Filipe

1987 Novos dados para o conhecimento do Urbanismo de Faro em época Moderna Ana Rosa 
1995 Um exemplo de Arqueologia Urbana em Alcoutim: o Antigo Edifício dos CTT Marco Fernandes / Marta Dias / Alexandra Gradim / Virgílio Lopes / Susana Gómez Martínez

2007 Palácio dos Ferrazes (Rua das Flores/Rua da Vitória, Porto): a cocheira de Domingos Oliveira Maia

Francisco Raimundo

2021 As muitas vidas de um edifício urbano: História, Arqueologia e Antropologia no antigo Recreatório Paroquial de Penafiel Helena Bernardo / Jorge Sampaio / Marta Borges

2035 O convento de Nossa Senhora da Esperança de Ponta Delgada: o contributo da arqueologia para o conhecimento de um monumento identitário João Gonçalves Araújo / N’Zinga Oliveira

2047 Arqueologia na ilha do Corvo... em busca da capela de Nossa Senhora do Rosário Tânia Manuel Casimiro / José Luís Neto / Luís Borges / Pedro Parreira

2059 Perdidos à vista da Costa. Trabalhos arqueológicos subaquáticos na Barra do Tejo Jorge Freire / José Bettencourt / Augusto Salgado

2071 Arqueologia marítima em Cabo Verde: enquadramento e primeiros resultados do projecto CONCHA

José Bettencourt / Adilson Dias / Carlos Lima / Christelle Chouzenoux / Cristóvão Fonseca / Dúnia Pereira / Gonçalo Lopes / Inês Coelho / Jaylson Monteiro / José Lima / Maria Eugénia Alves / Patrícia Carvalho / Tiago Silva

2085 Trabalhos arqueológicos na Cidade Velha (Ribeira Grande de Santiago, Cabo Verde): reflexões sobre um projecto de investigação e divulgação patrimonial André Teixeira / Jaylson Monteiro / Mariana Mateus / Nireide Tavares / Cristovão Fonseca / Gonçalo C. Lopes / Joana Bento Torres / Dúnia Pereira / André Bargão / Aurélie Mayer / Bruno Zélie / Carlos Lima / Christelle Chouzenoux / Inês Henriques / Inês Pinto Coelho / José Lima / Patrícia Carvalho / Tiago Silva

2103 A antiga fortificação de Quelba / Khor Kalba (E.A.U.). Resultados de quatro campanhas de escavações, problemáticas e perspectivas futuras Rui Carita / Rosa Varela Gomes / Mário Varela Gomes / Kamyar Kamyad

2123 Colónias para homens novos: arqueologia da colonização agrária fascista no noroeste ibérico Xurxo Ayán Vila / José Mạ . Señorán Martín 


\title{
A OCUPAÇÃO PALEOLÍTICA DA MARGEM ESQUERDA DO BAIXO MINHO: A INDÚS- TRIA LIITICA DO SIITIO DE PEDREIRAS 2 (MONÇÃO, PORTUGAL) E A SUA INTEGRAÇÃO NO CONTEXTO REGIONAL
}

\author{
Carlos Ferreira ${ }^{1}$, João Pedro Cunha-Ribeiro² ${ }^{2}$, Sérgio Monteiro-Rodrigues ${ }^{3}$, Eduardo Méndez-Quintas ${ }^{4}$, \\ Pedro Xavier ${ }^{5}$, José Meireles ${ }^{6}$, Alberto Gomes ${ }^{7}$, Manuel Santonja ${ }^{8}$, Alfredo Pérez-González ${ }^{9}$
}

\begin{abstract}
RESUMO
A crescente realização de trabalhos arqueológicos em jazidas paleolíticas permite atualmente uma melhor compreensão do tecno-complexo Acheulense à escala peninsular, e a sua integração no contexto africano e euroasiático. No presente trabalho pretende-se aprofundar a discussão em torno das características tecnológicas das indústrias líticas peninsulares da segunda metade do Pleistocénico Médio, através da análise da indústria lítica da jazida de Pedreiras 2 (Monção, Alto Minho). Da realização de trabalhos de campo no local, no contexto do Projeto Miño-Minho, resultou a recolha de materiais associáveis ao tecno-complexo Acheulense, que testemunham a ocupação da região numa área onde até recentemente se conheciam achados isolados de materiais coevos, e cujos dados cronométricos permitem enquadrar a sua cronologia na segunda metade do Pleistocénico Médio. Palavras-chave: Pleistocénico Médio; Paleolítico Inferior; Indústria lítica; Acheulense de grandes lascas; Baixo Minho.
\end{abstract}

\begin{abstract}
The recent increase of archaeological survey has allowed a better definition of the Acheulean techno-complex in the Iberian Peninsula, and its integration in the African and Eurasian context. This paper aims to extend the discussion around the technological features of the peninsular lithic industries of the second half of the Middle Pleistocene, through the presentation of the data from Pedreiras 2 (Monção, Alto Minho). The site excavation, on the scope of the Miño-Minho Project, allowed to recover lithic artefacts associated with the Acheulean techno-complex, testifying human occupation in a region where, until recently, only isolated remains were known, and whose chronological data fits its chronology into the second half of the Middle Pleistocene.

Keywords: Middle Pleistocene; Lower Palaeolithic; Lithic industry; Large flake Acheulean (LFA); Lower Minho basin.
\end{abstract}

1. Faculdade de Letras, Universidade de Lisboa; carlos.felipeı1@gmail.com.

2. Faculdade de Letras, Universidade de Lisboa; Centro de Arqueologia da Universidade de Lisboa (UNIARQ); Lab2pt; jpcunharibeiro@letras.ulisboa.pt.

3. Faculdade de Letras, Universidade do Porto; Centro de Investigação Transdisciplinar "Cultura, Espaço e Memória” (CITCEM); sergiomonteirorodrigues@gmail.com.

4. Grupo de Estudos de Arqueoloxía, Antigüidade e Territorio (GEAAT), University of Vigo, Campus As Lagoas, 32004 Ourense, Spain; eduardo.mendez.quintas@uvigo.es.

5. UMinho; Lab2pt; pedroxavy@gmail.com.

6. UMinho; Lab2pt; jmeireles@uaum.uminho.pt.

7. Faculdade de Letras, Universidade do Porto; Centro de Estudos de Geografia e Ordenamento do Territorio (CEGOT); albgomes@ gmail.com.

8. Centro Nacional de Investigacion sobre la Evolucion Humana (CENIEH), Burgos; manuel.santonja@cenieh.es.

9. IDEA, Instituto de Evolución en África, Covarrubias 36, 28010 Madrid; alfredopg41@hotmail.com. 


\section{INTRODUÇÃO}

Os trabalhos arqueológicos de prospeção e de escavação realizados ao longo das últimas décadas têm fornecido novos dados acerca do tecno-complexo Acheulense peninsular, e o seu enquadramento no contexto africano e euroasiático. Em termos cronológicos, documenta-se a multiplicação exponencial do número de jazidas com indústrias tecno-tipologicamente enquadráveis num LFA (large flake Acheulean - Sharon, 2007, 2008, 2009, 2010, 2011) a partir do MIS 13, estendendo-se até ao MIS 6 (Rubio-Jara \& alii, 2016; Santonja \& Villa, 1990; Santonja \& Pérez-González, 2010; Santonja \& alii, 2016; Méndez-Quintas \& alii, 2019; 2020a; 2020b), embora alguns autores considerem as indústrias dos sítios de La Boella (Tarragona), e de Cueva Negra del Estrecho del Río Quípar (Múrcia), como testemunhos das primeiras indústrias acheulenses peninsulares numa cronologia compreendida entre 1.o Ma e o.8 Ma (Mosquera \& alii, 2015; Vallverdú \& alii, 2014; Walker \& alii, 2013).

A maioria dos dados disponíveis para o estudo do Acheulense peninsular, que evidencia manifestas afinidades face ao Acheulense africano, provém do estudo dos materiais líticos recolhidos nos terraços fluviais das principais bacias hidrográficas atlânticas (associados aos terraços médios, a cotas compreendidas entre os $+40-20 \mathrm{~m}$ ), em função deste tipo de formas conterem depósitos sedimentares e, consequentemente, conservarem vestígios das ocupações humanas do passado, não obstante o facto de a sua integridade ser condicionada pelas dinâmicas de sedimentação/erosão fluvial (Chauhan \& alii, 2017; Santonja \& Villa, 199o; Santonja \& Pérez-González, 2010; Santonja \& alii, 2016). Neste sentido, e englobados num contexto mais amplo, destacam-se os estudos realizados recentemente na bacia hidrográfica do rio Minho (Cunha-Ribeiro $\&$ alii, 2017, 2018; Demuro \& alii, 2020; Méndez-Quintas, 2007, 2008, 2017; Méndez-Quintas \& alii, 2018a, 2018b, 2018c, 2019, 2020a, 2020b).

As diferenças de ritmo e de intensidade que caracterizaram o estudo do Paleolítico do Baixo Minho no século passado (Cunha-Ribeiro \& alii, 2017, 2018; Méndez-Quintas, 2017; Méndez-Quintas $\mathbb{Z}$ alii, 2018a, 2019, 2020a) materializaram-se no desenvolvimento irregular da exploração do potencial arqueológico da região. Consequentemente, a produção de um conhecimento assimétrico entre as duas margens constituía uma anomalia no estudo do Paleolítico Inferior da Península Ibérica, tendo em conta, justamente, que a maior parte do registo arqueológico desta época se concentra nos depósitos das principais bacias fluviais da vertente atlântica (Méndez-Quintas \& alii, 202ob). Por outro lado, embora a investigação arqueológica tenha sido pontualmente acompanhada pela realização de estudos geomorfológicos (Lautensach, 1945; Teixeira, 1944, 1952), só recentemente foi possível ultrapassar a impossibilidade de correlacionar sequências relativas entre os terraços fluviais e os materiais arqueológicos (Demuro \& alii, 2020; Méndez-Quintas \& alii, 2020a; Viveen $\&$ alii, 2012).

Estimulado pela multiplicação dos trabalhos na margem direita, e reunindo investigadores nacionais e estrangeiros, o projeto Miño/Minho (Os primeiros habitantes do Baixo Minho. Estudo das ocupações pleistocénicas da região), surgiu, precisamente, da tentativa de ultrapassar a assimetria no estudo das ocupações pleistocénicas em cada uma das margens do Baixo Minho. A realização de trabalhos de prospeção e de escavação no território entre Melgaço e Caminha, ao longo dos últimos quatro anos, tem permitido redefinir e aprofundar o entendimento da ocupação paleolítica da margem esquerda do Baixo Minho, correlacionando materiais arqueológicos e depósitos fluviais (Cunha-Ribeiro \& alii, 2017, 2018). Efetivamente, o esforço combinado das novas investigações permite assimilar, de forma mais detalhada, as características tecnológicas das primeiras ocupações humanas da região, cronologicamente enquadráveis na segunda metade do Pleistocénico Médio (Demuro \& alii, 202O; Méndez-Quintas \& alii, 2019, 2020a, 2020b). Neste contexto, destaca-se, na sua margem esquerda, a jazida de Pedreiras 2 (Monção, Alto Minho), cujos resultados do estudo da indústria lítica, tendo em conta a caracterização tecno-morfológica e tecno-económica das indústrias acheulenses peninsulares, se apresentam em seguida.

\section{PEDREIRAS 2: ENQUADRAMENTO GEOGRÁFICO E GEOMORFOLÓGICO}

O sítio arqueológico de Pedreiras 2 (CNS - 35273) localiza-se no Concelho de Monção, na área da União de Freguesias de Messegães, Valadares e Sá. Situado perto do túnel que passa por baixo da ligação de Monção a Melgaço (EN 202), encontra-se em relação com um afloramento do terraço fluvial do rio 
Minho implantado a +40 m acima do nível atual do rio (Figura 1).

A bacia hidrográfica do rio Minho, com uma extensão de cerca de $17027 \mathrm{~km} 2$, é a bacia hidrográfica mais relevante do Noroeste peninsular, contendo um importante registo sedimentar do Pleistocénico, composto principalmente por terraços fluviais e leques aluviais (Ribeiro, Moreira, 1986; Méndez-Quintas $\mathbb{E}$ alii, 2020a). No seu percurso, o rio Minho, que desagua no Oceano Atlântico, erode variadas litologias, gerando distintas paisagens, sendo que as suas condições geográficas e climáticas permitem defini-lo como um rio atlântico, com um fluxo máximo após as chuvas de inverno (Méndez-Quintas \& alii, 202Oa). A região conhecida como "Baixo Minho" cobre os $85 \mathrm{~km}$ mais ocidentais de um rio com mais de 350 $\mathrm{km}$, preservando um extenso registo morfológico, sedimentar e arqueológico do Pleistocénico Médio (Méndez-Quintas \& alii, 202Ob). Como referido anteriormente, ao longo do século passado realizaram-se, de forma pontual, estudos geomorfológicos que pretendiam distinguir os terraços fluviais do Baixo Minho "potentes niveles con asociaciones de litofacies Gh, Gp y Gt características de rellenos de estruturas acanaladas. Intercalados o a techo de estas facies clásticas, como respuesta a la fase final de colmatación de estos canales o a procesos de acreción vertical, se identifican facies de arenas y fangos" (Méndez-Quintas, 2017, p. 524). Procurando ultrapassar a variedade de perspetivas relativamente ao número e à altimetria dos terraços (que exibem uma variabilidade espacial ao longo da bacia devido a fatores litológicos e à interação com redes de falhas pré-existentes), nos últimos anos têm-se realizado estudos interdisciplinares centrados no mapeamento e na caracterização geomorfológica do sistema de terraços e dos depósitos fluviais associados. Paralelamente, têm-se desenvolvido pesquisas centradas na análise estratigráfica, na caracterização das diferentes unidades geológicas, e na correlação entre depósitos e vestígios de ocupações humanas do passado, através da escavação de um conjunto de sítios arqueológicos de maior interesse, e da obtenção de datações absolutas por ressonância paramagnética eletrónica (ESR) e luminescência opticamente estimulada (OSL) em quartzo sedimentar (Méndez-Quintas \& alii, 2020a).

Os dados resultantes das investigações recentemente realizadas possibilitam uma melhor compreensão das características da bacia hidrográfica do Baixo
Minho, individualizando-se geomorfologicamente nove níveis de terraços, "with relative heights above the current floodplain of +4-7 $\mathrm{m}(\mathrm{Tr}),+13-17 \mathrm{~m}\left(\mathrm{~T}_{2}\right)$, +21-29 $\mathrm{m}\left(\mathrm{T}_{3}\right),+3 \mathrm{O}-39 \mathrm{~m}\left(\mathrm{~T}_{4}\right),+45-51 \mathrm{~m}\left(\mathrm{~T}_{5}\right),+53-61$ $\mathrm{m}$ (T6), +65-77 m (T7), +78-89 $\mathrm{m}$ (T8) and +91-108 m (T9)" (Méndez-Quintas $\&$ alii, 2020a, p. 6). Os terraços fluviais do rio Minho, sobretudo de acumulação, e associados essencialmente às dinâmicas sedimentares do rio, foram formados entre o Pleistocénico Inicial e o Pleistocénico Final, propondo-se a seguinte cronologia provisória "as plausible for the lower Miño terrace system: $\mathrm{T} 1=<\mathrm{MIS}_{4}, \mathrm{~T}_{2}=$ MIS 6-5, T3 = MIS 8-7, T4 = MIS 9-8, T5 = MIS 12-11, $\mathrm{T} 6=\mathrm{MIS} 14-12, \mathrm{~T} 7=\mathrm{MIS} 17-15, \mathrm{~T} 8=21-17$ and T9 $=$ 25-22" (Idem, p. 9). Embora estes dados cronométricos possam vir a ser otimizados mediante a realização de datações complementares, permitem situar a formação dos terraços T2-T7 no Pleistocénico Médio. É justamente a este período cronológico que se têm associado numerosos sítios paleolíticos identificados entre $+40 \mathrm{~m} \mathrm{e}+13 \mathrm{~m}$ (a.l.a.), com indústrias líticas características de um LFA, mas também indústrias do Paleolítico Médio (Figura 2), dados que sugerem uma relevante ocupação humana da bacia hidrográfica do rio Minho a partir da segunda metade do Pleistocénico Médio (Méndez-Quintas \& alii, 2018b; 2019; 2020a; 2020b). Além disso, é importante referir que, apesar de ter sido proposta a presença de artefactos líticos de indústrias mais arcaicas em terraços acima dos $+40 \mathrm{~m}$ (a.l.a.), e, consequentemente, com cronologias anteriores a 500 ka, (Cano Pan \& alii, 1997; Villar Quinteiro, 2012), a potencial insegurança estratigráfica da localização dos materiais, e o debate em torno da sua natureza antrópica, não permitem assegurar a existência de evidências que testemunhem uma presença humana anterior ao Pleistocénico Médio na região (Méndez-Quintas $\&$ alii, 2O2Ob).

\section{O TRABALHO DE CAMPO}

O sítio de Pedreiras 2 foi alvo de trabalhos de escavação entre 2016 e 2017 por uma equipa de investigadores ibéricos. Destes trabalhos, resultou a recolha de materiais líticos talhados acheulenses em excelente estado físico, integrados em depósitos coluvionares canalizados, clásticos e matriz-suportados, que se encaixam em sedimentos finos de origem fluvial com apreciável potência (Cunha-Ribeiro \& alii, 2017). 


\section{METODOLOGIA}

No desenvolvimento do presente trabalho aplicou-se um conjunto de princípios metodológicos centrados na análise e caracterização tecno-tipológica da indústria lítica de Pedreiras 2. Os parâmetros tecnológicos e tipológicos aferidos seguem critérios de análise anteriormente descritos por Cunha-Ribeiro (1999) e Méndez-Quintas (2017), visando, deste modo, criar condições que permitam integrar o sítio de Pedreiras 2 nos resultados conhecidos para a margem direita, e estabelecer, eventualmente, outros paralelos. O estudo realizado baseou-se na abordagem subjacente ao conceito de cadeia operatória (Bar Yosef \& Van Peer, 2009; Boëda, Geneste \& Meignen, 1990; Inizan \& alii, 1995; Soressi \& Geneste, 2011), apesar da identificação de cadeiras operatórias no Paleolítico Inferior ser bastante complexa, em função da variabilidade que caracteriza este tipo de indústrias (Boëda, Geneste \& Meignen, 1990).

Tendo em conta que os materiais arqueológicos recolhidos em 2016 e em 2017 provêm de áreas fisicamente distintas (Figura 3), embora próximas (Cunha-Ribeiro \& alii, 2017), optou-se por estudar isoladamente os artefactos das duas campanhas. Os materiais de 2016 procedem de uma intervenção realizada no corte de um caminho relativamente paralelo à variante da EN 202, a partir do qual se estabeleceu uma sondagem para sul, e no talude anexo ao mesmo. O seu contexto sedimentar corresponde a depósitos de génese coluvionar canalizados em sedimentos fluviais finos areno-siltosos, que se integram numa estratigrafia complexa, onde, a par de algumas bolsas de areias, surgem vestígios de canais seccionados de depósitos coluvionares. Por outro lado, os materiais de 2017 foram recolhidos nos trabalhos realizados na plataforma sobranceira ao talude, a sul da área intervencionada em 2016. Apesar de se ter concluído que os níveis de coluvionamento apresentavam uma orientação e desenvolvimento diferentes do esperado, o contexto sedimentar dos artefactos exumados em 2017 permite a sua articulação com os identificados no ano anterior.

\section{RESULTADOS DO ESTUDO DO MATERIAL LÍTICO DE PEDREIRAS 2}

Embora o material de ambas as campanhas seja proveniente de áreas fisicamente isoladas, mas próximas, o estudo global do espólio, e o seu contex- to sedimentar, confirmam a hipótese inicialmente avançada de que estamos na presença de uma coleção homogénea (ao nível das matérias-primas, do estado físico das peças, da estatística das principais dimensões de ambos os conjuntos, e das suas características tecno-tipológicas), pelo que, em segui$\mathrm{da}$, se apresentam os resultados do estudo global da indústria.

Da análise da totalidade do material (200 peças) destacam-se algumas tendências acerca das características da indústria lítica do sítio de Pedreiras 2. Relativamente à matéria-prima utilizada, à semelhança do que se reconhece noutros sítios da região, constata-se que os tipos de rochas selecionados para a sua manipulação e transformação correspondem a dois grandes grupos: os quartzitos e os quartzos, disponíveis de forma abundante nos terraços fluviais próximos da jazida, sob a forma de seixos rolados. Assinala-se o predomínio do quartzito (65\%) sobre o quartzo (35\%), não se registando diferenças notáveis entre as distintas categorias tecnológicas, à exceção dos LCTs (large cutting tools), elaborados exclusivamente em quartzitos (Gráfico 1). Paralelamente, quanto ao seu estado físico, as peças apresentam um bom estado de conservação (146 peças classificadas como "arestas vivas", 46 peças classificadas como "pouco roladas" e apenas 8 peças "muito roladas"). Em relação à distribuição do material por categoria tecnológica (Gráfico 2), documenta-se o predomínio dos produtos de debitagem ("debitage" - 40\%; "debris" - 17\%), seguidos dos núcleos $(17 \%)$, e dos produtos configurados (utensílios $12 \%$; LCTs $-10 \%$ ), para além dos seixos rolados não trabalhados de origem exógena (4\%), maioritariamente de quartzo (cinco peças em seis).

Relativamente aos núcleos inventariados, destaca-se a utilização preferencial do quartzito (68\%) como matéria-prima, tendo-se excluído desta análise os seixos testados (incluídos na fase de aquisição). Explorados a partir de calhaus rolados, e através de percutores duros, prevalecem os núcleos com um só plano de percussão (73\%), predominando os planos de percussão corticais (83\%). Os padrões de redução são, regra geral, muito simples e expeditos, sendo notório o domínio dos esquemas monopolares unifaciais (14 núcleos). Para além dos esquemas monopolares, também existem exemplos de estratégias bipolares bifaciais (três), periféricas unifaciais (duas) e ortogonais bifaciais (duas). Com exemplos únicos, registou-se um núcleo multipolar unifacial, 
um núcleo monopolar bifacial, um núcleo periférico bifacial, um núcleo centrípeto, um núcleo discoide (em quartzo), e a utilização da técnica de redução bipolar sobre bigorna num núcleo de quartzo, realçando-se a presença de um giant core de quartzito na jazida. Os núcleos apresentam uma exploração sumária, com um número médio de cinco levantamentos (dois o valor mais baixo, e doze o valor mais alto), conservando em mais de $90 \%$ dos casos um volume suficiente para continuar a produzir suportes.

Em relação às lascas, ressalta igualmente a utilização preferencial do quartzito $(74 \%)$, sendo comum a existência de lascas fraturadas, essencialmente devido a acidentes de tipo Siret. Evidenciam-se as lascas de talão cortical (52\%) face às lascas de talão liso (35\%), estando também presentes exemplares residuais com talão diedro ( $9 \%)$, facetado ( $2 \%$ ), suprimido ( $1 \%$ ) e punctiforme (1\%). Em termos da percentagem de vestígios de córtex, regista-se a presença assinalável de lascas não corticais (<25\% - 29 lascas), para além de oito lascas semi-corticais (50$75 \%$ ), seis lascas corticais ( $>75 \%$ ), e três lascas com vestígios corticais (25-50\%), resultados compatíveis com uma produção realizada na própria jazida. Fora deste âmbito, documenta-se a presença significativa de lascas com dorso natural (25 lascas), tendencialmente aplanado e invasor, ou marginal e abrupto, o que indicia o desenvolvimento lateral da debitagem, correlacionável com a exploração de seixos rolados de quartzito enquanto suportes predominantes da matéria-prima utilizada. Além disso, registaram-se também cinco lascas resultantes da configuração de LCTs, duas lascas discoides, uma lasca kombewa, uma lasca bipolar sobre bigorna, uma lasca de reavivamento de peças retocadas, e uma ponta levallois. Os bolbos estão bem desenvolvidos, e o padrão das extrações anteriores à obtenção da lasca evidencia uma variabilidade reduzida, dominando os padrões de natureza monopolar (70\%), sobre os padrões ortogonais (11\%), multipolares (10\%), bipolares (5\%), centrípetos (3\%) e periféricos (1\%). As lascas apresentam uma média de 2,7 levantamentos (variam entre zero e onze levantamentos), assinalando-se a diferença entre o número médio de negativos das lascas de quartzito $(2,9)$ e de quartzo $(2,1)$.

Os produtos configurados encontram-se representados na indústria lítica por um conjunto de utensílios diversos e LCTs. Tendo em conta os utensílios diversos, 18 peças correspondem a utensílios sobre lasca, e 6 a utensílios sobre seixo. Relativamente aos utensílios sobre lasca, predominam os suportes não corticais (onze), para além da presença de suportes com vestígios corticais (quatro) e de lascas com dorso natural (três). As peças apresentam um número reduzido de retoques, sendo o retoque maioritariamente marginal. Em termos tipológicos, não existe qualquer tipo de estandardização, identificando-se "simples" lascas retocadas (seis), repartindo-se os restantes exemplares entre cinco entalhes, três denticulados, dois raspadores (um dos quais sobre uma lasca entame), um furador, e um utensílio compósito. Quanto aos utensílios sobre seixo, realça-se um grande seixo apontado. Dentro dos LCTs, exclusivamente em quartzito, destacam-se os machados de mão e os bifaces, estando também presentes exemplares de esboços de peças bifaciais. Relativamente aos machados de mão, desde um ponto de vista tecno-tipológico (Tixier, 1956), a forma mais representada é o "tipo o" (cinco exemplares), documentando-se apenas um exemplar de "tipo 1 ", e os materiais foram elaborados tanto em lascas com vestígios corticais (três peças), como em lascas semi-corticais (três peças). A configuração dos bordos realizou-se mediante a utilização de percutor duro, e, como é habitual neste tipo de peças, a intensidade da configuração não é muito elevada. Regra geral, as peças exibem uma configuração marginal, também direcionada para suprimir o talão e o bolbo, registando-se uma configuração/regularização mais intensa de ambos os bordos em duas peças. Os bifaces analisados correspondem a bifaces-outil (Böeda, Geneste \& Meignen, 1990), e, apesar de ser um conjunto numericamente reduzido, apresentam variabilidade formal (Bordes, 1961), com morfologias amigdaloides (um biface amigdaloide com talão, um biface amigdaloide típico), discoides (um biface discoide com talão), e limandes (um biface proto-limande com talão), para além de um proto biface. Para a sua elaboração selecionaram-se tanto seixos (duas peças), como lascas (duas peças), não sendo possível determinar o suporte de um dos exemplares. A intensidade da configuração é bastante elevada, no sentido em que o anverso de todas as peças está quase, ou totalmente, sem córtex, constatando-se que os bifaces elaborados a partir de seixo rolado são os que apresentam uma maior transformação por talhe. Além disso, é relevante referir que a sua configuração se realizou maioritariamente através de percutor duro, reconhecendo-se, pelo menos num caso, a aplicação de percutor brando/mole na regularização da peça. 
Em termos gerais, o valor reduzido da amostragem, e o facto de os atributos apresentarem uma grande variação, não permite perspetivar mais correlações entre o suporte, a dimensão, a morfologia, a silhueta e a simetria da peça, ou com uma maior intensidade de intervenção e transformação de determinadas formas e/ou suportes.

\section{DISCUSSÃO: A INDÚSTRIA LÍTICA DE PEDREIRAS 2}

Com base na interpretação da indústria lítica, e do seu contexto estratigráfico, é possível destacar algumas tendências. De um ponto de vista geoarqueológico, o material é proveniente de um contexto secundário, integrado em depósitos coluvionares, atestado, por exemplo, no rácio desproporcional aproximado de um núcleo para duas lascas. No entanto, o bom grau de conservação da grande maioria do material, e a presença simultânea de artefactos de diferentes tamanhos e pesos (desde pequenas lascas e subprodutos não específicos, inferiores a $30 \mathrm{~mm}$, a um giant core), são observações pertinentes que sugerem, e pressupõem, uma mobilização reduzida do conjunto, conferindo-lhe uma relativa homogeneidade. Estes argumentos serão indicadores de uma origem próxima do local, correlacionando-se, provavelmente, com depósitos de baixa energia de natureza fluvial.

Como referido anteriormente, não obstante o facto de o material ser proveniente de duas áreas fisicamente isoladas, mas próximas, estamos perante uma coleção homogénea. Neste sentido, podem salientar-se algumas observações, nomeadamente o facto de se constatarem duas realidades diferenciáveis. Por um lado, a presença de LCTs na jazida, ou a presença residual de lascas de configuração deste tipo de peças, é sugestiva de uma realidade associada ao uso e à manutenção de produtos configurados, característicos das indústrias acheulenses. À semelhança da situação registada nos conjuntos estudados na margem direita, onde os LCTs são habitualmente configurados fora das jazidas (Méndez-Quintas, 2017), estes materiais teriam sido introduzidos na jazida já em fase de uso. Por outro lado, constata-se a existência de uma realidade principal, maioritária, relacionada com uma indústria mais expedita, focada na produção de lascas. Relativamente aos núcleos, é nesta dinâmica que se interpreta a presença de seixos testados (embora a abundância de matéria-prima justifique a parca relevância dos elementos associados à fase de aquisição, e a reduzida exploração dos volumes); o facto de cerca de $71 \%$ dos núcleos ter apenas um plano de percussão; e, sobretudo, o predomínio de esquemas elementares (monopolares), à semelhança do padrão de exploração dos levantamentos da face dorsal das lascas. Quanto às lascas, o estudo da sua variabilidade tecno-tipológica, e do seu grau de corticalidade, também evidenciam resultados compatíveis com uma produção realizada no local, destacando-se a presença maioritária de lascas com dorso natural, ou de lascas não corticais ( $>25 \%$ ), que remetem para diferentes fases da exploração de um núcleo. Além disso, é de assinalar a reduzida dimensão dos produtos de debitagem (em concordância com a dimensão média da última lasca identificável nos núcleos), para além da presença de um conjunto de subprodutos de talhe não específicos, que atestam a realização de atividades de talhe no local, reforçando o predomínio dos elementos associados à fase de produção.

Consequentemente, o estudo da coleção permite associar a indústria lítica de Pedreiras 2 não a uma cadeia operatória direcionada para a obtenção e configuração de grandes lascas suporte, que foram introduzidas no local já em fase de uso, mas antes com uma realidade paralela que visa a obtenção de produtos de debitagem relativamente expeditos e simples, por vezes sumariamente retocados, elaborados maioritariamente a partir de seixos rolados de quartzito. Todavia, é importante ressalvar que a interpretação arqueológica do conjunto se encontra, naturalmente, subordinada à dimensão da amostragem (200 peças), e à sua posição estratigráfica. Efetivamente, ao analisar materiais provenientes de depósitos fluviais, é preciso ter em conta que existe um conjunto de fatores que condicionam a análise, nomeadamente:

- A dificuldade em definir a dimensão e a extensão da área ocupada;

- O impacto do contexto sedimentar e da natureza dos processos de formação do sítio na integridade da sua indústria lítica;

- O tempo envolvido na formação da jazida, visto que, muitas vezes, os conjuntos correspondem a acumulações de material descartado durante um período incerto, ao longo do tempo, sendo excecionais os casos em que se conservam períodos de ocupação curtos;

- E, por último, que a realização de compara- 
ções entre locais com base numa análise tecno-tipológica pode produzir observações ilusórias, se as diferentes variáveis envolvidas nos processos de formação não forem consideradas, uma vez que as disparidades podem ser consequência, não da funcionalidade da jazida, mas antes dos processos geoarqueológicos envolvidos na sua formação (Santonja \& Villa, 199o).

\section{EPÍLOGO: O SÍTIO DE PEDREIRAS 2 NO CONTEXTO DO PLEISTOCÉNICO MÉDIO DO BAIXO MINHO E DO OCIDENTE PENINSULAR}

A identificação da jazida paleolítica do sítio de Pedreiras 2 permitiu reunir duas centenas de materiais líticos talhados, entre os quais produtos configurados (bifaces e machados de mão) característicos das indústrias acheulenses, que, pelas suas características, e pela sua posição estratigráfica, testemunham a ocupação paleolítica da região durante a segunda metade do Pleistocénico Médio, inserindo-a num contexto muito mais amplo que abrange o território peninsular.

De um ponto de vista tecnológico, as indústrias acheulenses peninsulares caracterizam-se, à semelhança dos conjuntos africanos, pela gestão e consumo de grandes volumes de matéria-prima (giant cores), essencialmente de caráter local. Através de esquemas de exploração monopolares, bifaciais, ou multipolares, visa-se a produção de lascas de pequeno/médio formato, e de grandes suportes ( $>10 \mathrm{~cm}$ ), retocados, ou configurados, para a produção de utensílios como LCTs (large cutting tools), diferenciando-se, deste modo, dos conjuntos de lascas e núcleos olduvaienses (Méndez-Quintas \& alii, 2018a, 2019, 2O2ob; Santonja \& Pérez-González, 2010; Santonja, \& alii, 2016; Sharon, 2009; Sharon, 2010; Sharon \& Barsky 2016). No entanto, é essencial ter em conta que, em certas ocasiões, se tende a definir exclusivamente as indústrias acheulenses com base na presença, ou ausência, deste tipo de materiais configurados: "Realmente no es así, ya que la presencia o no de LCTs en un yacimiento, tiene componentes de índole funcional, sedimentario, de la disponibilidad de materias primas o de otros factores difíciles de diferenciar" (Méndez-Quintas, 2017, p. 39). Com efeito, paralelamente às cadeias operatórias de façonna$g e$, as cadeias operatórias de débitage teriam também uma importância assinalável (Santonja \& alii, 2016), dinâmica com a qual o sítio de Pedreiras 2 se parece relacionar: "Estos procesos aportaban lascas de pequeño o mediano formato y filo cortante, obtenidas mediante sistemas de explotación sencillos (monopolares longitudinales, multipolares y discoides) y podían ser transformadas posteriormente por retoque en utensilios más complejos" (Méndez-Quintas \& alii, 2018a, p. 17).

A segunda metade do Pleistocénico Médio é um período que, do ponto de vista tecnológico, se caracteriza no território peninsular pela coexistência de dois tecno-complexos claramente diferenciados: a presença de um conjunto significativo de sítios com abundantes concentrações de indústrias características de um LFA, que, após o MIS 9, coexistem com exemplos isolados de indústrias de tecnologia Early Middle Palaeolithic (EMP), associadas a cadeias operatórias ramificadas, com estratégias estandardizadas de exploração dos núcleos (discoide e Levallois), direcionadas para a produção de lascas, e de pequenos utensílios morfologicamente repetitivos, registando-se um decréscimo significativo do número de peças bifaciais (que, quando presentes, perdem a sua função de "utensílios", convertendo-se em suportes para a obtenção de utensílios sobre lasca). No entanto, durante todo este período, e sobretudo entre o intervalo do MIS 9-6, prevalece uma estabilidade tecnológica que reforça as afinidades africanas do Acheulense do sudoeste europeu, por oposição à realidade do noroeste europeu (Cologne $\&$ alii, 2013; Méndez-Quintas $\&$ alii, 202ob; Santonja $\mathbb{\&}$ alii, 2016; Turq $\&$ alii, 2010; Sharon, 2009; Sharon, 2010; Sharon \& Barsky, 2016).

Uma das regiões que regista uma extensa concentração de indústrias características de um LFA, é, precisamente, a zona do Baixo Minho, sendo que o intervalo cronológico para a presença humana nesta bacia hidrográfica (terraços entre $+40-20 \mathrm{~m}$ a.l.a.) durante a segunda metade do Pleistocénico Médio (MIS 9-6), como referido anteriormente, apresenta correspondência com as grandes bacias ibéricas, e com algumas do sudoeste europeu (Méndez-Quintas $\mathbb{8}$ alii, 2020b). Efetivamente, a realização de trabalhos arqueológicos na área tem documentado sítios com indústrias típicas de um LFA, com vastos conjuntos de bifaces e machados de mão (elaborados em grandes lascas obtidas a partir da exploração de giant cores), tais como os sítios de Arbo (Méndez-Quintas $\&$ alii, 2018c, 2019), As Gándaras de Budiño (Méndez-Quintas, 2007, 2008; Méndez-Quintas \& alii, 
2018a), Fillaboa e Porto Maior (Méndez-Quintas $\mathbb{E}$ alii, 2018c), na margem direita, e o sítio de Carvalhas (Cunha-Ribeiro $\&$ alii, 2017), em fase de estudo, na margem esquerda. Neste contexto, o sítio de Pedreiras 2 contribui para reforçar a relevância da ocupação humana na região durante a segunda metade do Pleistocénico Médio, associável ao tecno-complexo Acheulense. A composição da sua cadeia operatória (Gráfico 3 e Tabela 1), caracterizada pelo predomínio dos produtos relacionados com a fase de produção (57,5\%), face aos elementos da fase de consumo $(21,5 \%)$, para além da reduzida importância dos elementos de aquisição (3,5\%), é análoga à composição das cadeias operatórias das jazidas da margem direita (e do documentado na generalidade dos contextos acheulenses peninsulares), à exceção do nível PM4 de Porto Maior. Com efeito, a fase de consumo é aquela que apresenta uma maior variabilidade entre sítios, caracterizando-se este nível por uma cadeia operatória dominada por elementos de consumo (91,9\%), com um conjunto notável de LCTs com densidade e dimensões que apenas regista paralelos nos contextos africanos e levantinos, dados relevantes a favor da hipótese da origem africana do Acheulense peninsular (Méndez-Quintas, 2018b). Além disso, a indústria lítica de Pedreiras 2 apresenta um conjunto de características que, uma vez mais, estão em sintonia com a realidade documentada nas jazidas do Baixo Minho, e noutros conjuntos acheulenses peninsulares, nomeadamente:

- A prevalência de esquemas de exploração mais elementares, fundamentalmente monopolares;

- A total ausência de sistemas de redução levallois;

- O predomínio de lascas simples, ou de lascas com dorso natural;

- A presença maioritária de talões corticais, face aos talões lisos, e a presença muito reduzida de talões diedros e facetados;

- A existência residual de suportes provenientes de núcleos com um padrão de exploração organizada (exclusivamente discoide);

- A preponderância de padrões de exploração monopolares na face dorsal das lascas;

- A presença comum de utensílios retocados sobre lasca, caracterizados pela aplicação de retoques de extensão marginal, que transformam de forma limitada a morfologia original dos suportes;

- E, por último, a frequência generalizada de LCTs, maioritariamente bifaces-outil, e machados de mão tipo o.
Em síntese, a análise do espólio da indústria lítica de Pedreiras 2, baseada na exploração dos recursos locais de matéria-prima (essencialmente seixos rolados de quartzito), testemunha, globalmente, o predomínio de cadeias operatórias de debitagem relativamente expeditas e simples, o que, à semelhança do verificado noutros conjuntos das principais bacias hidrográficas ibéricas, se correlaciona com a abundância local da matéria-prima utilizada. Paralelamente ao predomínio de produtos de debitagem resultantes de estratégias de exploração pouco elaboradas, assinala-se a presença de um conjunto de LCTs, provavelmente introduzidos no local em fase de uso. Neste sentido, a coleção de Pedreiras 2, articulada com o terraço fluvial a $+40 \mathrm{~m}$ (a.l.a.), associada ao tecno-complexo Acheulense (no contexto da variabilidade tecno-tipológica e tecno-económica que exibe à escala peninsular), e coerente com o contexto cronológico e tecnológico das jazidas da margem direita (e de outros pontos da Península Ibérica), contribui para consolidar o panorama da ocupação humana da região durante a segunda metade do Pleistocénico Médio. Adicionando novos dados sobre as características tecnológicas que definem esta etapa, testemunha a importância arqueológica da margem esquerda para o estudo do Paleolítico do curso final do Rio Minho, uma zona estratégica do ponto de vista da diversidade de recursos e da abundância de matéria-prima. Consequentemente, fornece-se um contributo para ultrapassar a assimetria entre as duas margens, ao dar um novo impulso ao conhecimento do Paleolítico da região, anteriormente documentado de forma esparsa e dissemina$\mathrm{da}$, esperando-se que o desenvolvimento favorável de novos trabalhos contribua para ampliar o nosso entendimento acerca do comportamento humano na região, e as suas características tecnológicas.

\section{Nota}

O presente trabalho foi elaborado pelo primeiro signatário a partir do estudo da indústria lítica por si realizado no contexto do seminário de fim de Licenciatura, no âmbito da sua participação no projeto Minho-Miño ao longo dos últimos quatro anos. 


\section{BIBLIOGRAFIA}

BAR-YOSEF, Ofer; VAN PEER, Philip (2009) - The Chaîne Opératoire approach in Middle Paleolithic archaeology. Current Anthropology, Vol. 5o, issue 1, Chicago: University of Chicago Press, pp. 103-131.

BOËDA, Eric; GENESTE, Jean-Michel; MEIGNEN, Liliane (1990) - Identification de Chaînes Opératoires Lithiques du Palaeolithique Ancien et Moyen. Paléo, 2, pp. 43-80.

BORDES, François (1961) - Typologie du Paleolithique ancien et moyen. CREP, Bordeaux.

CANO PAN, Juan; AGUIRRE, Emiliano; GILES PACHECO, Francisco; GRACIA PRIETO, Javier; SANTIAGO PÉREZ, Antonio; MATA ALMONTE, Esperanza; GUTIÉRREZ LÓPEZ, José; DÍAZ DEL OLMO, Fernando; BAENA ESCUDERO, Rafael;BORJA, Francisco (1997) - Evolución del Pleistoceno en la cuenca baja del Miño, sector La Guardia-Tuy. Secuencia de los primeros poblamientos humanos y registro arqueológico. In RODRÍGUEZ VIDAL, Julio, ed. - Cuaternario Ibérico, pp. 201-212.

CHAUHAN, Parth; BRIDGLAND, David; MONCEL, Marie-Hèlene; ANTOINE, Pierre; BAHAIN, Jean-Jacques; BRIANT, Rebecca; CUNHA, Pedro Proença; DESPRIÉE, Jackie; LIMONDIN-LOZOUET, Nicole; LOCHT, Jean-Luc; MARTINS, António; SCHREVE, Danielle; SHAW, Andrew; VOINCHET, Pierre; WESTAWAY, Rob; WHITE, Mark; WHITE, Tom (2017) - Fluvial deposits as an archive of early human activity: progress during the 20 years of the Fluvial Archives Group. Quaternary Science Reviews, 166, pp. 114-149.

COLOGNE, David; HERNÁDEZ, Marion; LELOUVIER, Laure-Amélie; MERCIER, Norbert; MOURRE, Vincent; BUSSEUIL, Nathalie (2013) - Paléolithique ancien et Paléolithique moyen ancien dans le piémont pyrénéen occidental: relations entre chaînes opératoires, continuités et ruptures. In JAUBERT, Jacques; FORUMENT, Nathalie \& DEPAEPE, Pascal, eds. - Transitions, ruptures et continuité en Préhistoire. Société préhistorique française, Volume 1, pp.119-137.

CUNHA-RIBEIRO, João Pedro (1999) - O Acheulense no Centro de Portugal: o Vale do Lis. Contribuição para uma abordagem tecno-tipológica das suas indústrias líticas e problemática do seu contexto cronoestratigráfico. Tese de Doutoramento, Lisboa: Universidade de Lisboa, 3 vols, p. 692.

CUNHA-RIBEIRO, João Pedro; MONTEIRO-RODRIGUES, Sérgio; GOMES, Alberto; MÉNDEZ-QUINTAS, Eduardo; MEIRELES, José; PÉREZ-GONZÁLEZ, Alfredo; SANTONJA, Manuel (2017) - Ocupações pleistocénicas da margem esquerda do Baixo Minho (Miño/Minho 2). Objetivos e primeiros resultados de um projeto transfronteiriço. In ARNAUD, José \& MARTINS, Andrea, eds. - Arqueologia em Portugal / 2017 - Estado da Questão, Associação dos Arqueólogos Portugueses, pp. 303-318.
CUNHA-RIBEIRO, João Pedro; MONTEIRO-RODRI-GUES, Sérgio; MÉNDEZ-QUINTAS, Eduardo; GOMES, Alberto; MEIRELES, José; PÉREZ-GONZÁLEZ, Alfredo; SANTONJA, Manuel (2018) - O Paleolítico de Melgaço. Vestígios arqueológicos dos primeiros habitantes do Concelho. Boletim de Cultura de Melgaço, pp. 117-150.

DEMURO, Martina;ARNOLD, Lee; DUVAL, Mathieu; MÉNDEZ-Quintas, Eduardo; SANTONJA, Manuel; PÉREZ-GONZÁLEZ, Alfredo (2020) - Refining the chronology of Acheulean deposits at Porto Maior in the River Miño basin (Galicia, Spain) using a comparative luminescence and ESR dating approach. Quaternary International (2020).

LAUTENSACH, Hermann (1945) - Formação dos terraços interglaciários do Norte de Portugal e suas relações com os problemas da época glaciária. Publicações da Sociedade Geológica de Portugal, Porto, p. 44.

MÉNDEZ-QUINTAS, Eduardo (2007) - El yacimiento achelense de As Gándaras de Budiño. La industria en facies fluvial. Complutum, 18, pp. 27-45.

MÉNDEZ-QUINTAS, Eduardo (2008) - La industria lítica de las facies coluviales del Yacimiento Achelense de as Gándaras de Budiño. El Locus V en las excavaciones de Vi- dal Encinas. Zephyrus, LXII (2), Salamanca, pp. 41-61.

MÉNDEZ-QUINTAS, Eduardo (2017) - Caracterización y variabilidad tecnomorfológica de las industrias achelenses de la Cuenca Baja del Río Miño (NO de la Península Ibérica). Tesis Doctoral, Universidad de Burgos, Escuela Interuniversitaria de Posgrado en Evolucion Humana, CENIEH, Universidad de Alcalá, Universidad de Oviedo, p. 628.

MÉNDEZ-QUINTAS, Eduardo; SANTONJA, Manuel; PÉREZ-GONZÁLEZ, Alfredo; ARNOLD, Lee; CUNHA-RIBEIRO, João Pedro; DEMURO, Martina; DÍAZ-RODRÍGUEZ, Mikel; DUVAL, Mathieu; GOMES, Alberto; MEIRELES, José; MONTEIRO-RODRIGUES, Sérgio; SERODIO DOMÍNGUEZ, Andrea (2018a) - El yacimiento achelense de As Gándaras de Budiño: Síntesis y perspectivas después de 50 años de desencuentros. Estudos do Quaternario, 19, pp. 1-22.

MÉNDEZ-QUINTAS, Eduardo; SANTONJA, Manuel; PÉREZ-GONZÁLEZ, Alfredo; DUVAL, Mathieu; DEMURO, Martina; ARNOLD, Lee (2018b) - First evidence of an extensive Acheulean large cutting tool accumulation in Europe from Porto Maior (Galicia, Spain). Scientific Reports, $8(1), 3082$.

MÉNDEZ-QUINTAS, Eduardo; PÉREZ-GONZÁLEZ, Alfredo; LEDO BERNÁRDEZ, Manuel; SERODIO DOMÍNGUEZ, Andrea (2018c) - La industria lítica del yacimiento achelense de Arbo (Pontevedra). Variables del paleolítico antiguo de Galicia en el contexto peninsular. Zephyrus, LXXXII, pp.3-34.

MÉNDEZ-QUINTAS, Eduardo; DEMURO, Martina; ARNOLD, Lee; DUVAL, Mathieu; PÉREZ-GONZÁLEZ, Alfredo; SANTONJA, Manuel (2019) - Insights into the late 
stages of the Acheulean technocomplex of Western Iberia from the Arbo site (Galicia, Spain). Journal of Archaeological Science: Reports, 27, 101934.

MÉNDEZ-QUINTAS, Eduardo; SANTONJA, Manuel; PÉREZ-GONZÁlEZ, Alfredo, ARNOLD, Lee; DEMURO, Martina; DUVAL, Mathieu (2O2Oa) - A multidisciplinary overview of the lower Miño River terrace system (NW Iberian Peninsula). Quaternary International (2020).

MÉNDEZ-QUINTAS, Eduardo; SANTONJA, Manuel; ARNOLD, Lee; CUNHA-RIBEIRO, João Pedro; DA SILVA, Pedro; DEMURO, Martina; DUVAL, Mathieu; GOMES, Alberto; MEIRELES, José; MONTEIRO-RODRIGUES, Sérgio; PÉREZ-GONZÁLEZ, Alfredo (2020b) - The Acheulean Technocomplex of the Iberian Atlantic Margin as an Example of Technology Continuity Through the Middle Pleistocene. Journal of Paleolithic Archaeology (2020).

MOSQUERA, Marina; SALADIÉ, Palmira; OLLÉ, Andreu; CÁCERES, Isabel; HUGUET, Rosa; VILLALAÍN, Juan José; CARRANCHO, Angel; BOURLÈS, Didier; BRAUCHER, Régis; VALLVERDÚ, Josep (2015) - Barranc de la Boella (Catalonia, Spain): an Acheulean elephant butchering site from the European late Early Pleistocene. Journal of Quaternary Science, 30 (7), pp. 651-666.

RIBEIRO, Maria Luísa; MOREIRA, Armando (1986) - Notícia Explicativa da Folha 1-B: Monção, escala 1:50.00o. Serviços Geológicos de Portugal, Lisboa.

RUBIO-JARA, Susana; PANERA, Joaquín; RODRÍGUEZDE-TEMBLEQUE, Juan; SANTONJA, Manuel; PÉREZGONZÁLEZ, Alfredo (2016) - Large flake Acheulean in the middle of Tagus basin (Spain): Middle stretch of the river Tagus valley and lower stretches of the rivers Jarama and Manzanares valleys. Quaternary International, 411, pp. 349-366.

SANTONJA, Manuel; VILLA, Paola (1990) - The Lower Paleolithic of Spain and Portugal. Journal of World Prehistory, 4 (1), pp. 45-94.

SANTONJA, Manuel; PÉREZ-GONZÁLEZ, Alfredo (2010) - Mid-Pleistocene Acheulean industrial complex in the Iberian Peninsula. Quaternary International, 223-224, pp. $154-161$.

SANTONJA, Manuel; PÉREZ-GONZÁLEZ, Alfredo; PANERA, Joaquín; RUBIO-JARA, Susana; MÉNDEZ-QUINTAS, Eduardo (2016) - The coexistence of Acheulean and Ancient Middle Palaeolithic technocomplexes in the Middle Pleistocene of the Iberian Peninsula. Quaternary International, 411, pp. 367-377.

SHARON, Gonen (2007) - Acheulian Large Flake Industries: Technology, Chronology, and Significance. BAR International Series 1701, $236 \mathrm{p}$.

SHARON, Gonen (2008) - The impact of raw material on Acheulian large flake production. Journal of Archaeological Science, 35 (5), pp. 1329-1344.
SHARON, Gonen (2009) - Acheulian Giant Core Technology. Current Anthropology, 50 (3), pp. 335-367.

SHARON, Gonen (2010) - Large flake Acheulian. Quaternary International, 223-224, pp. 226-233.

SHARON, Gonen (2011) - Flakes Crossing the Straits? Entame Flakes and Northern Africa-Iberia Contact During the Acheulean. African Archaeological Review, 28 (2), pp. 125-140.

SHARON, Gonen; BARSKY, Deborah (2016) - The emergence of the Acheulian in Europe - a look from the east. Quaternary International, 411, pp. 25-33.

SORESSI, Marie; GENESTE, Jean-Michel (2011) - The History and Efficacy of the Chaîne Opératoire Approach to Lithic Analysis: Studying Techniques to Reveal Past Societies in an Evolutionary Perspective. PaleoAnthropology, pp. 334-350.

TEIXEIRA, Carlos (1944) - Tectónica Plio-Pleistocénica do Noroeste Peninsular. Boletim da Sociedade Geológica de Portugal, Vol. IV, fasc. 1-2, pp. 19-41.

TEIXEIRA, Carlos (1952) - Os terraços da parte portuguesa do rio Minho. Comunicações dos Serviços Geológicos de Portugal, Tomo XXXIII, Lisboa, pp. 221-246.

TIXIER, Jacques (1956) - Le hachereau dans l'Acheuléen Nord-Africain. Notes typologiques. Congrès Préhistorique de France, $X V^{e m e}$ sesión. Poitiers, pp. 914-923.

TURQ, Alain; BRENET, Michel; COLONGE, David; JARRY, Marc; LELOUVIER, Laure-Amélie; O’FARRELL, Magen; JAUBERT, Jacques (2010) - The first human occupations in southwestern France: a revised summary twenty years after the Abbeville/Saint Riquier colloquium. Quaternary International, 223-224, pp. 383-398.

VALLVERDÚ, Josep; SALADIÉ, Palmira; ROSAS, Antonio; HUGUET, Rosa; CÁCERES, Isabel; MOSQUERA, Marina; GARCIA-TABERNERO, Antonio; ESTALRRICH, Almudena; LOZANO-FERNÁNDEZ, Iván; PINEDA-ALCALÁ, Antonio; CARRANCHO, Ángel; VILLALAÍN, Juan; BOURLÈS, Didier; BRAUCHER, Régis; LEBATARD, Anne; VILALTA, Jaume; ESTEBAN-NADAL, Montserrat; BENNASAR, Maria; BASTIR, Marcus; LÓPEZ-POLÍN, Lucía; OLLÉ, André; VERGÉS, Josep; ROS-MONTOYA, Sergio; MARTÍNEZ-NAVARRO, Bienvenido; GARCÍA, Ana; MARTINELL, Jordi; EXPÓSITO, Isabel; BURJACHS, Francesc; AGUSTÍ, Jordi; CARBONELL, Eduald (2014) - Age and date for early arrival of the Acheulian in Europe (Barranc de la Boella, la Canonja, Spain). PLoS One 9 (7), e103634.

VILLAR QUINTEIRO, Rosa (2012) - Primeras ocupaciones humanas en el noroeste peninsular. Gallaecia, 31, pp. 5-16.

VIVEEN, Willem; BRAUCHER, Régis; BOURLÈS, Didier; SCHOORL, Jeroen; VELDKAMP, Tom.; VAN BALEN, Ronald.;WALLINGA, Jakob; FÉRNANDEZ-MOSQUERA, 
Daniel;VIDAL-ROMANI, Juan Roman; SANJURJO-SANCHEZ, Jorge (2012) - A o.65 Ma chronology and incision rate assessment of the NW Iberian Miño River terraces. Global and Planetary Change, 94-95, pp. 82-10o.

WALKER, Michael John; LÓPEZ-MARTÍNEZ, Mariano; CARRIÓN-GARCÍA, José; RODRÍGUEZ-ESTRELLA, Tomás; SAN-NICOLÁS DEL-TORO, Miguel; SCHWENNINGER, Jean-Luc; LÓPEZ-JIMÉNEZ, Antonio; ORTEGA-
-RODRIGÁÑEZ, Jon; HABER-URIARTE, María; POLO-CAMACHO, Juan Luis; GARCÍA-TORRES, Jesús; CAMPILLO-BOJ, Matías; AVILÉS-FERNÁNDEZ, Azucena; ZACK, Winston (2013) - Cueva Negra del Estrecho del Río Quípar (Murcia, Spain): A late Early Pleistocene hominin site with an "Acheulo-Levalloiso-Mousteroid" Palaeolithic assemblage. Quaternary International 294, pp. 135-159.

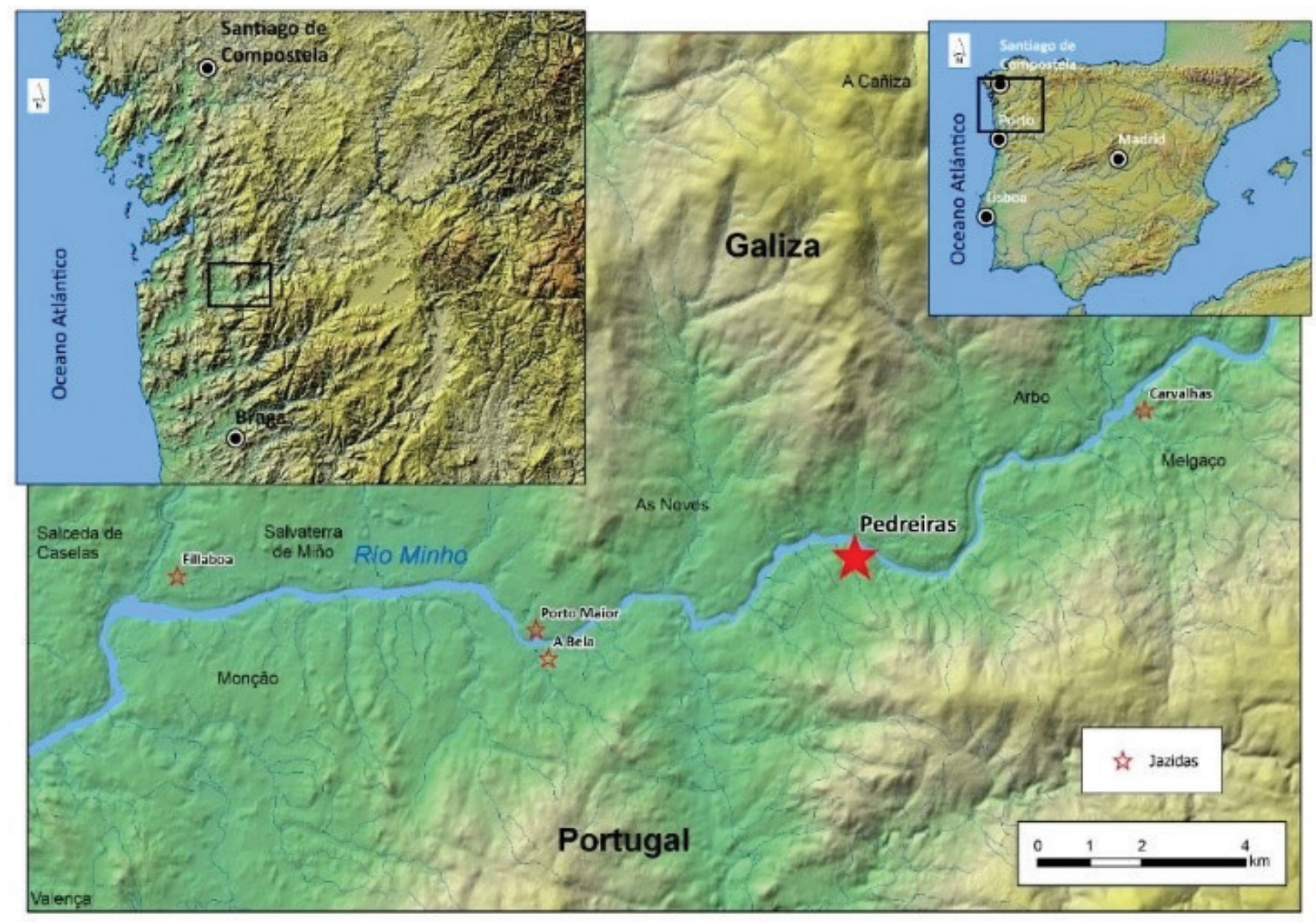

Figura 1 - Localização geográfica da jazida de Pedreiras 2.

$\mathrm{N}$

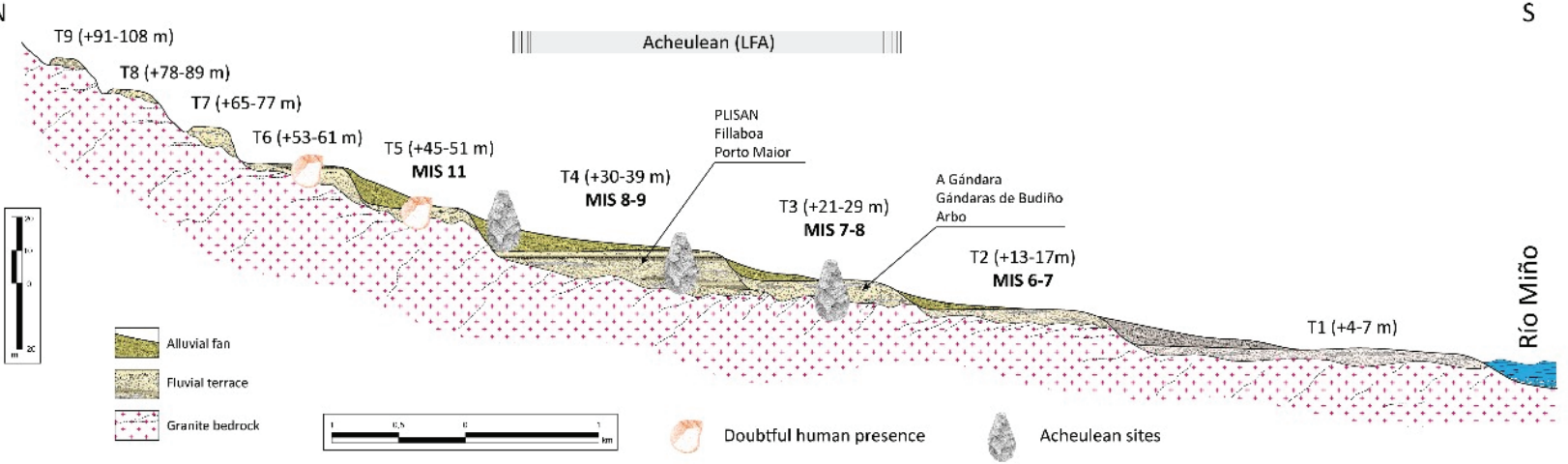

Figura 2 - Esquema dos níveis de terraços fluviais do Baixo Minho (Méndez-Quintas \& alii, 2020a). 

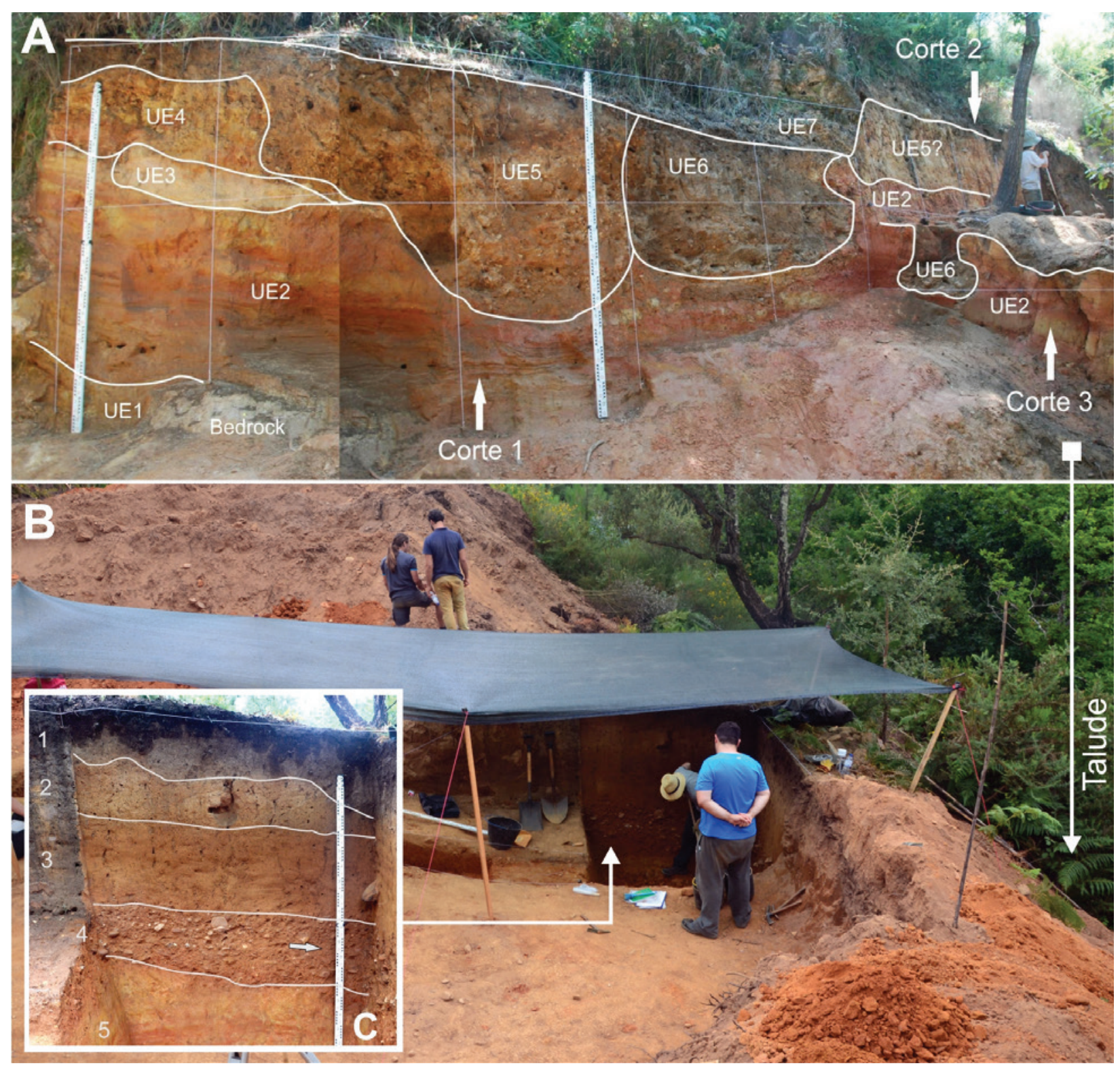

Figura 3 - Jazida de Pedreiras 2 (Monção). A - Talude onde se identificou o biface que conduziu à descoberta da estação arqueológica. Descrição estratigráfica sumária: UE1, UE2, UE3 - Depósitos fluviais arenosos com estratificação horizontal, arqueologicamente estéreis (cota da base: $35 \mathrm{~m}$ acima do leito atual do rio Minho); UE4, UE5, UE6 - Depósitos coluvionares em canais que se entrerrecortam; UE7 - Solo atual. B - Plataforma sobre o talude, intervencionada em 2016 (sondagem 1) e 2017. C - Sequência estratigráfica observada na área da sondagem 1: UE1 - Solo atual; UE2 e UE3 - Depósito areno-siltoso, possivelmente eólico; UE4 - Depósito coluvionar onde surge o material lítico talhado; UE5-Depósito fluvial arenoso, correspondente à UE2 do talude. 

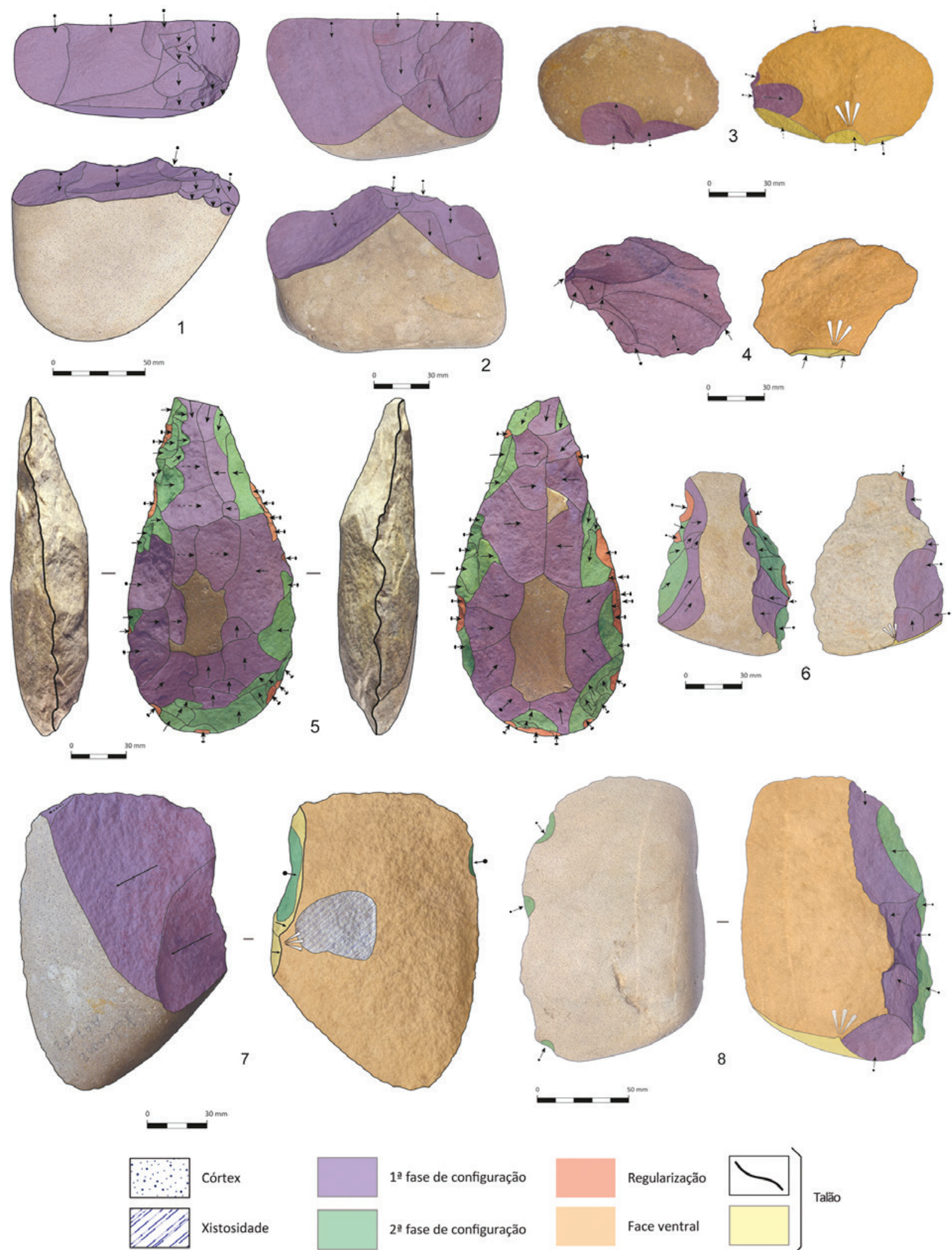

12 fase de configuração

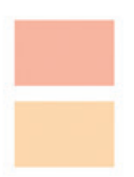

Regularização

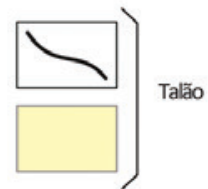

Figura 4 - Jazida Acheulense de Pedreiras 2: Núcleos monopolares unifaciais sobre seixos rolados de quartzito (1-2); Lascas de configuração de LCT em quartzito (3-4); Biface configurado sobre seixo rolado de quartzito (5); Machados de mão "tipo o" sobre lascas de quartzito (6-8). 


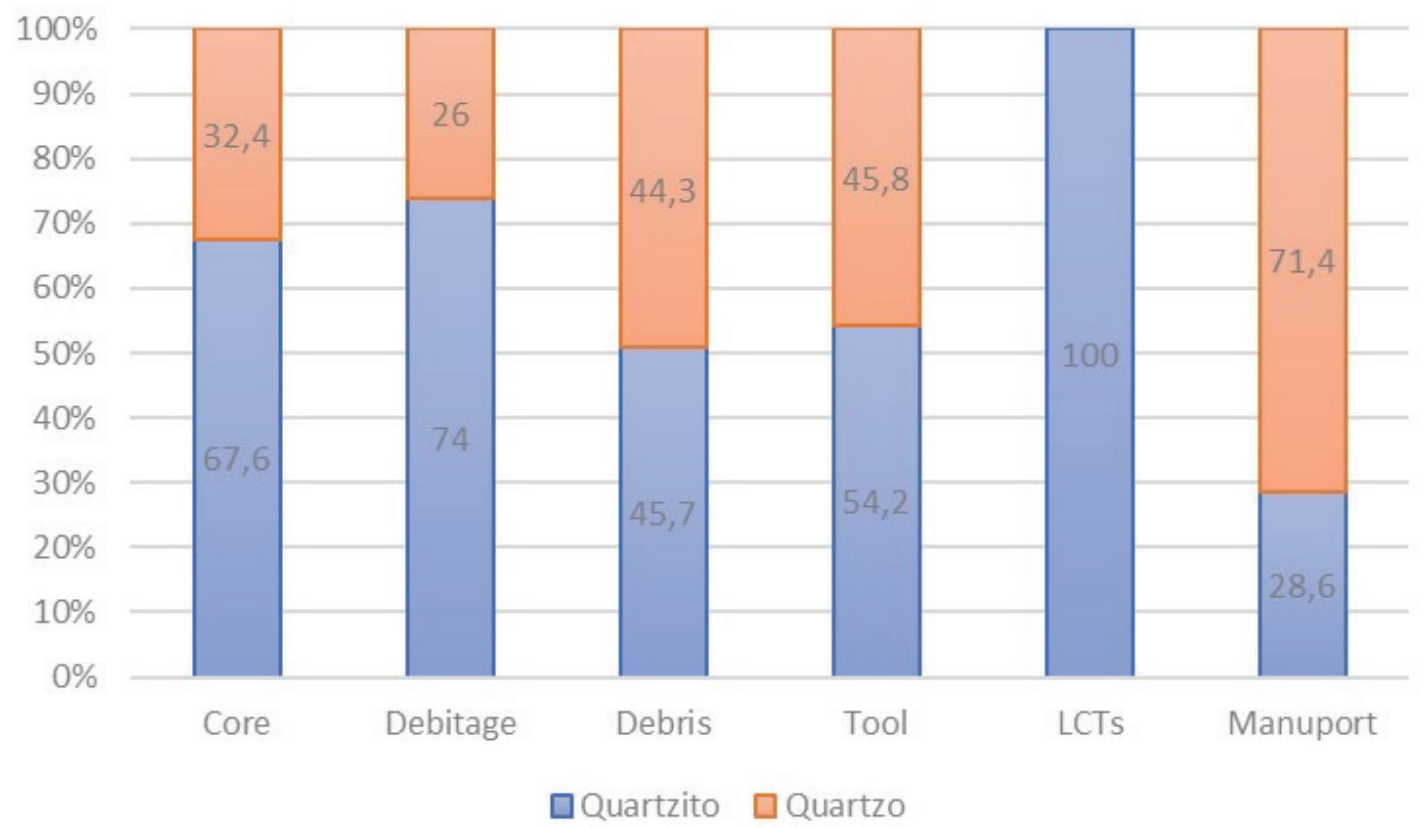

Gráfico 1 - Distribuição de efetivos por categorias tecnológicas com base na matéria-prima.

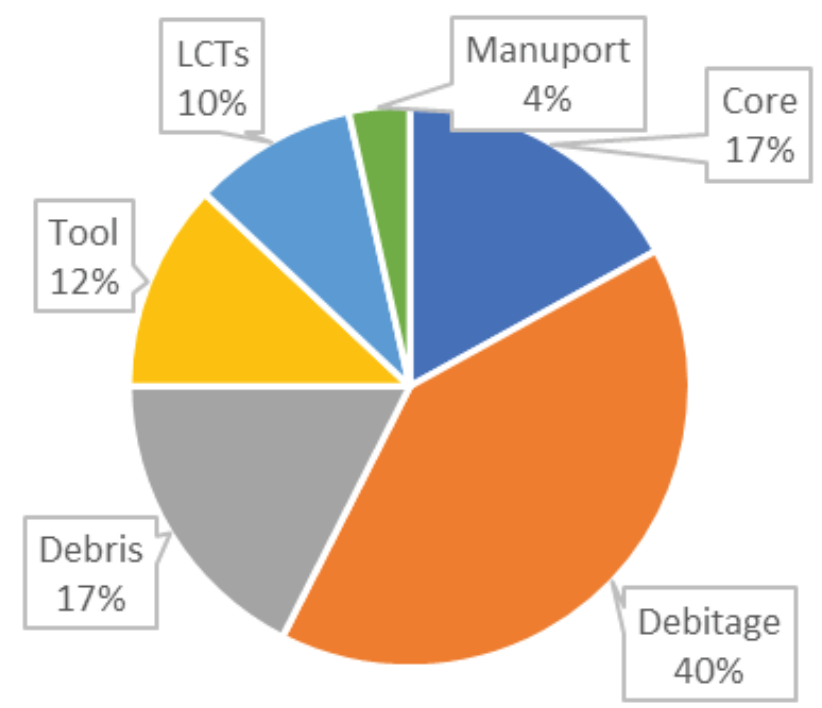

- Core " Debitage " Debris " Tool " LCTs " Manuport

Gráfico 2 - Distribuição do material por categoria tecnológica. 


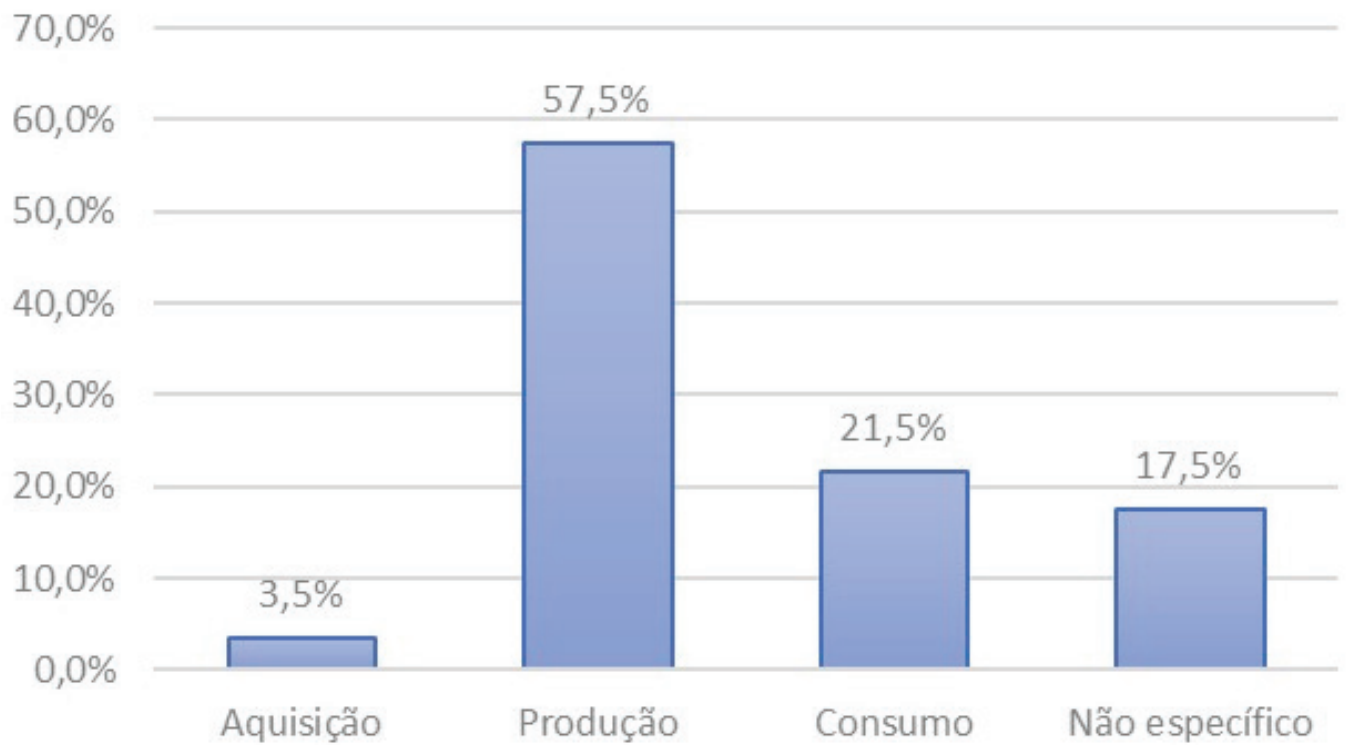

Gráfico 3-Representatividade das diferentes fases da cadeia operatória.

\begin{tabular}{|c|c|c|c|c|c|c|c|c|c|c|c|c|c|c|c|c|c|c|c|c|c|c|c|c|c|}
\hline \multirow{3}{*}{\multicolumn{2}{|c|}{ Elementos tecnológicos }} & \multicolumn{8}{|c|}{ Campanha de 2016} & \multicolumn{8}{|c|}{ Campanha de 2017} & \multicolumn{8}{|c|}{ Total } \\
\hline & & \multicolumn{4}{|c|}{ Quartzito } & \multicolumn{4}{|c|}{ Quartzo } & \multicolumn{4}{|c|}{\begin{tabular}{l|l} 
Quartzito & \\
\end{tabular}} & \multicolumn{4}{|c|}{ Quartzo } & \multicolumn{4}{|c|}{ Quartzito } & \multicolumn{4}{|c|}{ Quartzo } \\
\hline & & \multicolumn{2}{|c|}{ Total } & \multicolumn{2}{|c|}{ Utensilios } & \multicolumn{2}{|c|}{ Total } & \multicolumn{2}{|c|}{ Utensilios } & \multicolumn{2}{|c|}{ Total } & \multicolumn{2}{|c|}{ Utensilios } & To & tal & Uter & sílios & To & tal & Uter & isilios & & tal & Uter & isilios \\
\hline & 0. Aquisição & $\mathrm{n}$ & $\%$ & $\mathrm{n}$ & $\%$ & $\mathrm{n}$ & $\%$ & $\mathrm{n}$ & $\%$ & $\mathrm{n}$ & $\%$ & $\mathrm{n}$ & $\%$ & $\mathrm{n}$ & $\%$ & $n$ & $\%$ & $\mathrm{n}$ & $\%$ & $\mathrm{n}$ & $\%$ & $\mathrm{n}$ & $\%$ & $\mathrm{n}$ & $\%$ \\
\hline 0.1 & Seixos rolados & 0 & 0,0 & 3 & 50,0 & 0 & 0,0 & 0 & 0,0 & 0 & 0,0 & 2 & 28,6 & 0 & 0,0 & 1 & 14,3 & 0 & 0,0 & 5 & 38,5 & 0 & 0,0 & 1 & 9,1 \\
\hline 0.2 & Seixos rolados não trabalhados & 1 & 1,2 & 0 & 0,0 & 5 & 11,1 & 0 & 0,0 & 0 & 0,0 & 0 & 0,0 & 0 & 0,0 & 0 & 0,0 & 1 & 0,8 & 0 & 0,0 & 5 & 8,9 & 0 & 0,0 \\
\hline 0.3 & Percutores/bigornas & 0 & 0,0 & 0 & 0,0 & 0 & 0,0 & 0 & 0,0 & 1 & 2,9 & 0 & 0,0 & 0 & 0,0 & 0 & 0,0 & 1 & 0,8 & 0 & 0,0 & 0 & 0,0 & 0 & 0,0 \\
\hline 0.4 & Seixos testados & 2 & 2,3 & 0 & 0,0 & 2 & 4,4 & 0 & 0,0 & 0 & 0,0 & 0 & 0,0 & 0 & 0,0 & 0 & 0,0 & 2 & 1,7 & 0 & 0,0 & 2 & 3,6 & 0 & 0,0 \\
\hline & 1. Descorticagem & $\mathrm{n}$ & $\%$ & $\mathrm{n}$ & $\%$ & $\mathrm{n}$ & $\%$ & $\mathrm{n}$ & $\%$ & $n$ & $\%$ & $\mathrm{n}$ & $\%$ & $\mathrm{n}$ & $\%$ & $\mathrm{n}$ & $\%$ & $\mathrm{n}$ & $\%$ & $\mathrm{n}$ & $\%$ & $n$ & $\%$ & $\mathrm{n}$ & $\%$ \\
\hline 1.1 & Lascas corticais (>75\%) & 3 & 3,5 & 0 & 0,0 & 3 & 6,7 & 0 & 0,0 & 0 & 0,0 & 0 & 0,0 & 0 & 0,0 & 0 & 0,0 & 3 & 2,5 & 0 & 0,0 & 3 & 5,4 & 0 & 0,0 \\
\hline 1.2 & Lascas semi-corticais $(50-75 \%)$ & 4 & 4,7 & 0 & 0,0 & 0 & 0,0 & 0 & 0,0 & 4 & 11,8 & 0 & 0,0 & 0 & 0,0 & 0 & 0,0 & 8 & 6,7 & 0 & 0,0 & 0 & 0,0 & 0 & 0,0 \\
\hline & 2. Produtos ordinários & $\mathrm{n}$ & $\%$ & $\mathrm{n}$ & $\%$ & $n$ & $\%$ & $\mathrm{n}$ & $\%$ & $\mathrm{n}$ & $\%$ & $\mathrm{n}$ & $\%$ & $\mathrm{n}$ & $\%$ & $n$ & $\%$ & $\mathrm{n}$ & $\%$ & $n$ & $\%$ & $n$ & $\%$ & $n$ & $\%$ \\
\hline 2.1 & Lascas não corticais (<25\%) & 9 & 10,5 & 1 & 16,7 & 11 & 24,4 & 2 & 50,0 & 6 & 17,6 & 2 & 28,6 & 3 & 27,3 & 6 & 85,7 & 15 & 12,5 & 3 & 23,1 & 14 & 25,0 & 8 & 72,7 \\
\hline 2.2 & Lascas com restos corticais (25-50\%) & 0 & 0,0 & 1 & 16,7 & 1 & 2,2 & 2 & 50,0 & 2 & 5,9 & 1 & 14,3 & 0 & 0,0 & 0 & 0,0 & 2 & 1,7 & 2 & 15,4 & 1 & 1,8 & 2 & 18,2 \\
\hline 2.3 & Lascas Kombewa & 1 & 1,2 & 0 & 0,0 & 0 & 0,0 & 0 & 0,0 & 0 & 0,0 & 0 & 0,0 & 0 & 0,0 & 0 & 0,0 & 1 & 0,8 & 0 & 0,0 & 0 & 0,0 & 0 & 0,0 \\
\hline & 3. Produtos com dorso & $\mathrm{n}$ & $\%$ & $\mathrm{n}$ & $\%$ & $n$ & $\%$ & $n$ & $\%$ & $\mathrm{n}$ & $\%$ & $n$ & $\%$ & $n$ & $\%$ & $n$ & $\%$ & $n$ & $\%$ & $n$ & $\%$ & $n$ & $\%$ & $n$ & $\%$ \\
\hline 3.1 & Lascas com dorso desbordante & 0 & 0 & 0 & 0 & 0 & 0 & 0 & 0 & 0 & 0 & 0 & 0 & 0 & 0 & 0 & 0 & 0 & 0 & 0 & 0,0 & 0 & 0 & 0 & 0 \\
\hline 3.2 & Lascas com dorso natural & 15 & 17,4 & 1 & 16,7 & 2 & 4,44 & 0 & 0 & 7 & 20,6 & 2 & 28,6 & 1 & 9,09 & 0 & 0 & 22 & 18,3 & 3 & 23,1 & 3 & 5,36 & 0 & 0 \\
\hline & 4. Produtos de padrão organizado & $\mathrm{n}$ & $\%$ & $\mathrm{n}$ & $\%$ & $\mathrm{n}$ & $\%$ & $\mathrm{n}$ & $\%$ & $\mathrm{n}$ & $\%$ & $\mathrm{n}$ & $\%$ & $\mathrm{n}$ & $\%$ & $n$ & $\%$ & $\mathrm{n}$ & $\%$ & $\mathrm{n}$ & $\%$ & $\mathrm{n}$ & $\%$ & $n$ & $\%$ \\
\hline 4.1 & Lascas levallois & 0 & 0,0 & 0 & 0,0 & 0 & 0,0 & 0 & 0,0 & 0 & 0,0 & 0 & 0,0 & 0 & 0,0 & 0 & 0,0 & 0 & 0,0 & 0 & 0,0 & 0 & 0,0 & 0 & 0,0 \\
\hline 4.2 & Pontas levallois & 1 & 1,2 & 0 & 0,0 & 0 & 0,0 & 0 & 0,0 & 0 & 0,0 & 0 & 0,0 & 0 & 0,0 & 0 & 0,0 & 1 & 0,8 & 0 & 0,0 & 0 & 0,0 & 0 & 0,0 \\
\hline 4.3 & Lascas discoides & 1 & 1,2 & 0 & 0,0 & 0 & 0,0 & 0 & 0,0 & 1 & 2,9 & 0 & 0,0 & 0 & 0,0 & 0 & 0,0 & 2 & 1,7 & 0 & 0,0 & 0 & 0,0 & 0 & 0,0 \\
\hline 4.4 & Pontas pseudo-levallois & 0 & 0,0 & 0 & 0,0 & 0 & 0,0 & 0 & 0,0 & 0 & 0,0 & 0 & 0,0 & 0 & 0,0 & 0 & 0,0 & 0 & 0,0 & 0 & 0,0 & 0 & 0,0 & 0 & 0,0 \\
\hline & 5. Núcleos & $\mathrm{n}$ & $\%$ & $\mathrm{n}$ & $\%$ & $n$ & $\%$ & $n$ & $\%$ & $\mathrm{n}$ & $\%$ & $n$ & $\%$ & $\mathrm{n}$ & $\%$ & $n$ & $\%$ & $\mathrm{n}$ & $\%$ & $\mathrm{n}$ & $\%$ & $n$ & $\%$ & $\mathrm{n}$ & $\%$ \\
\hline 5.1 & Núcleos sobre seixo & 15 & 17,4 & 0 & 0,0 & 3 & 6,7 & 0 & 0,0 & 4 & 11,8 & 0 & 0,0 & 2 & 18,2 & 0 & 0,0 & 19 & 15,8 & 0 & 0,0 & 5 & 8,9 & 0 & 0,0 \\
\hline 5.2 & Núcleos sobre lasca & 0 & 0,0 & 0 & 0,0 & 0 & 0,0 & 0 & 0,0 & 0 & 0,0 & 0 & 0,0 & 0 & 0,0 & 0 & 0,0 & 0 & 0,0 & 0 & 0,0 & 0 & 0,0 & 0 & 0,0 \\
\hline 5.3 & Núcleos em suporte indeterminado & 0 & 0,0 & 0 & 0,0 & 4 & 8,9 & 0 & 0,0 & 0 & 0,0 & 0 & 0,0 & 0 & 0,0 & 0 & 0,0 & 0 & 0,0 & 0 & 0,0 & 4 & 7,1 & 0 & 0,0 \\
\hline 5.4 & Fragmentos de núcleo & 2 & 2,3 & 0 & 0,0 & 0 & 0,0 & 0 & 0,0 & 0 & 0,0 & 0 & 0,0 & 0 & 0,0 & 0 & 0,0 & 2 & 1,7 & 0 & 0,0 & 0 & 0,0 & 0 & 0,0 \\
\hline & LCTs e prod.configuraçăo/regularizaçăo & $n$ & $\%$ & $\mathrm{n}$ & $\%$ & $n$ & $\%$ & $n$ & $\%$ & $\mathrm{n}$ & $\%$ & $n$ & $\%$ & $n$ & $\%$ & $n$ & $\%$ & $\mathrm{n}$ & $\%$ & $n$ & $\%$ & $\mathrm{n}$ & $\%$ & $n$ & $\%$ \\
\hline 6.1 & Lascas de regularização de retocados & 1 & 1,2 & 0 & 0,0 & 0 & 0,0 & 0 & 0,0 & 0 & 0,0 & 0 & 0,0 & 0 & 0,0 & 0 & 0,0 & 1 & 0,8 & 0 & 0,0 & 0 & 0,0 & 0 & 0,0 \\
\hline 6.2 & Lascas de configuração de LCT & 4 & 4,7 & 0 & 0,0 & 0 & 0,0 & 0 & 0,0 & 1 & 2,9 & 0 & 0,0 & 0 & 0,0 & 0 & 0,0 & 5 & 4,2 & 0 & 0,0 & 0 & 0,0 & 0 & 0,0 \\
\hline 6.3 & Fragmentos de peças retocadas & 0 & 0,0 & 0 & 0,0 & 0 & 0,0 & 0 & 0,0 & 0 & 0,0 & 0 & 0,0 & 0 & 0,0 & 0 & 0,0 & 0 & 0,0 & 0 & 0,0 & 0 & 0,0 & 0 & 0,0 \\
\hline 6.4 & LCTs e fragmentos & 16 & 18,6 & 0 & 0,0 & 0 & 0,0 & 0 & 0,0 & 3 & 8,8 & 0 & 0,0 & 0 & 0,0 & 0 & 0,0 & 19 & 15,8 & 0 & 0,0 & 0 & 0,0 & 0 & 0,0 \\
\hline & 7. Subprodutos não específicos & $\mathrm{n}$ & $\%$ & $\mathrm{n}$ & $\%$ & $\mathrm{n}$ & $\%$ & $\mathrm{n}$ & $\%$ & $\mathrm{n}$ & $\%$ & $\mathrm{n}$ & $\%$ & $\mathrm{n}$ & $\%$ & $\mathrm{n}$ & $\%$ & $\mathrm{n}$ & $\%$ & $\mathrm{n}$ & $\%$ & $\mathrm{n}$ & $\%$ & $\mathrm{n}$ & $\%$ \\
\hline 7.1 & Debris e peq. lascas (<30 mm) & 1 & 1,2 & 0 & 0,0 & 0 & 0,0 & 0 & 0,0 & 2 & 5,9 & 0 & 0,0 & 3 & 27,3 & 0 & 0,0 & 3 & 2,5 & 0 & 0,0 & 3 & 5,4 & 0 & 0,0 \\
\hline 7.2 & Fragmentos de lasca & 1 & 1,2 & 0 & 0,0 & 6 & 13,3 & 0 & 0,0 & 1 & 2,9 & 0 & 0,0 & 1 & 9,1 & 0 & 0,0 & 2 & 1,7 & 0 & 0,0 & 7 & 12,5 & 0 & 0,0 \\
\hline 7.3 & Chunks & 4 & 4,7 & 0 & 0,0 & 6 & 13,3 & 0 & 0,0 & 0 & 0,0 & 0 & 0,0 & 1 & 9,1 & 0 & 0,0 & 4 & 3,3 & 0 & 0,0 & 7 & 12,5 & 0 & 0,0 \\
\hline 7.4 & Fragmentos e lascas térmicas & 5 & 5,8 & 0 & 0,0 & 2 & 4,4 & 0 & 0,0 & 1 & 2,9 & 0 & 0,0 & 0 & 0,0 & 0 & 0,0 & 6 & 5,0 & 0 & 0,0 & 2 & 3,6 & 0 & 0,0 \\
\hline & Indeterminados & 0 & 0,0 & 0 & 0,0 & 0 & 0,0 & 0 & 0,0 & 1 & 2,9 & 0 & 0,0 & 0 & 0,0 & 0 & 0,0 & 1 & 0,8 & 0 & 0,0 & 0 & 0,0 & 0 & 0,0 \\
\hline & Total & 86 & & 6 & & 45 & & 4 & & 34 & & 7 & & 11 & & 7 & & 120 & & 13 & & 56 & & 11 & \\
\hline
\end{tabular}

Tabela 1 - Fases e subfases da cadeia operatória (organizada por matérias-primas). 


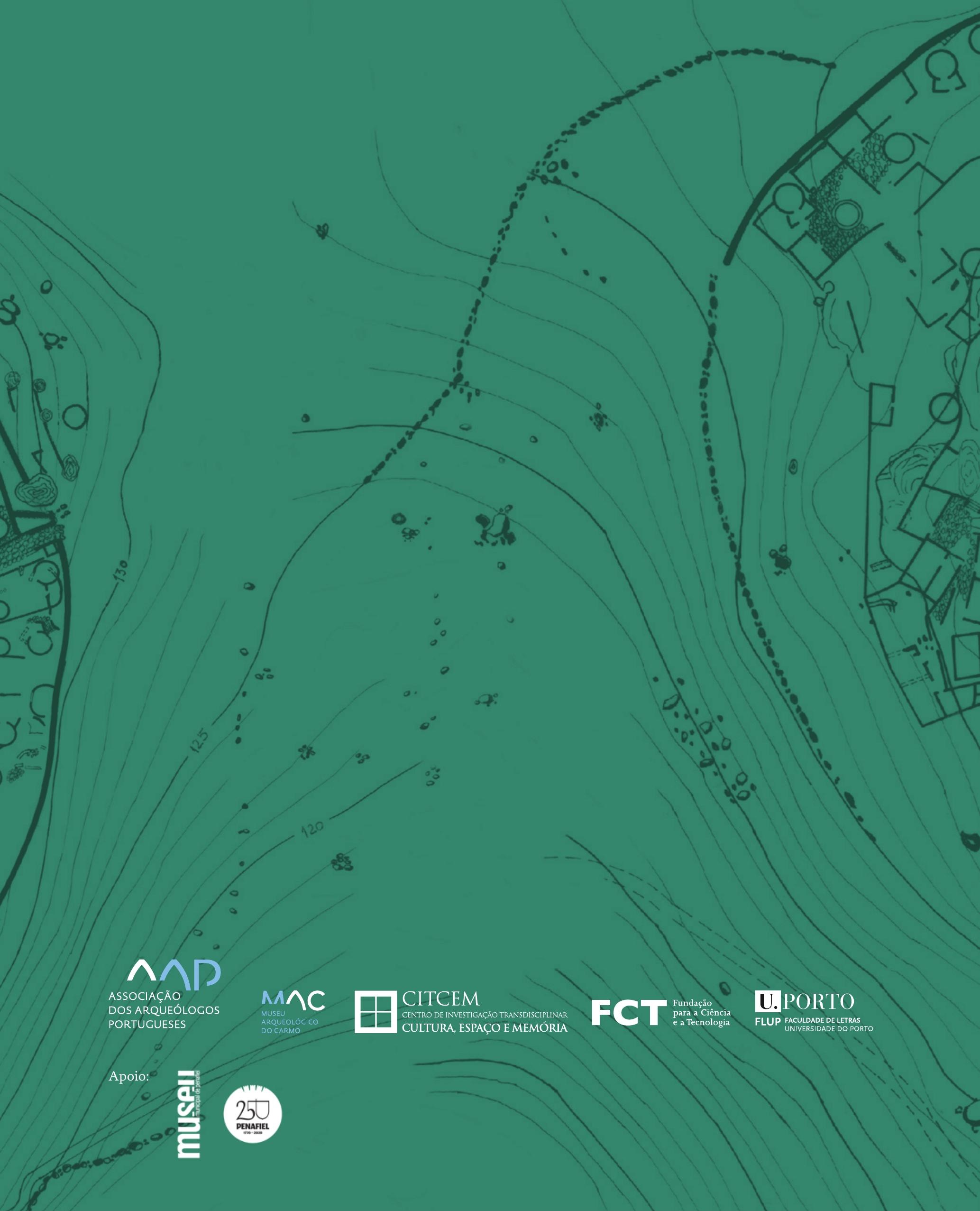

